\title{
INVESTIGATION OF SOOT OXIDATION BY COUPLING LII, SAXS AND SCATTERING MEASUREMENTS
}

Jérôme Yon ${ }^{1}$, François-Xavier Ouf ${ }^{2}$, Damien Hebert ${ }^{1}$, James Brian Mitchell ${ }^{3}$, Nadine Teuscher ${ }^{4}$, JeanLuc Le Garrec $^{3}$, Alexandre Bescond ${ }^{5}$, Werner Baumann ${ }^{4}$, Djoudi Ourdani ${ }^{6}$, Thomas Bizien ${ }^{7}$ and Javier Perez ${ }^{7}$.

${ }^{1}$ Normandie Univ, INSA Rouen, UNIROUEN, CNRS, CORIA, 76000 Rouen, France.

${ }^{2}$ Institut de Radioprotection et de Sureté Nucléaire (IRSN), PSN-RES, SCA, LPMA, Gif-sur-Yvette, 91192, France.

${ }^{3}$ Institut de Physique de Rennes, Université de Rennes I, 35042 Rennes, France.

${ }^{4}$ Institute for Technical Chemistry, Karlsruhe Institute of Technology, Germany.

${ }^{5}$ Environnement SA, 78304 POISSY, France

${ }^{6}$ Laboratoire de Physico-Chimie des Matériaux et Catalyse, Université de Bejaia, 06000 Bejaia, Algérie.

${ }^{7}$ Synchrotron SOLEIL, L'orme des Merisiers Saint-Aubin - BP 48, Gif-sur-Yvette, 91192, France.

\section{KEYWORDS}

Soot, oxidation, laser diagnostics, SAXS, fractals

\section{CORRESPONDING AUTHOR}

Dr Jérôme YON yon@coria.fr 


\begin{abstract}
This work presents an in-situ characterization of the oxidation of soot particles in flames by coupling three different techniques. Small Angle X-ray Scattering and Static Light Scattering were used in order to provide information on the size of the primary spheres and the aggregates respectively. Laser Induced Incandescence was also used to determine the soot volume fraction in the flame. Flame temperatures and soot residence time were also determined. These techniques were combined to provide a complete description of the impact of the oxidation process on soot aggregates (aggregate and primary sphere densities, size distributions). In order to limit the phenomena to oxidation, soot was generated upstream by a miniCAST generator and injected into a non-sooting flame. Amongst other results, it is shown that primary sphere diameter reduction is accompanied by an increase of the geometric standard deviation. This effect can be modeled by considering the transition from a volume (diffusion) to a surface (reaction) oxidation process.
\end{abstract}




\section{APPENDIX}

\begin{tabular}{|ll|}
\hline HAB & Height Above the Burner \\
SAXS & Small Angle X-ray Scattering \\
SLS & Static Light Scattering \\
LII & Laser Induced Incandescence \\
\hline
\end{tabular}

\begin{tabular}{|c|c|c|}
\hline$A$ & $\mathrm{~m} 2$ & Soot surface area \\
\hline$B_{a}$ and $B_{p}$ & $\begin{array}{c}\mathrm{m}^{-(\mathrm{Df}+1)} \text { and } \\
\mathrm{m}^{-(\mathrm{p}+1)}\end{array}$ & $\begin{array}{l}\text { Pre-factors of the power-law regimes for aggregates and } \\
\text { primary spheres }\end{array}$ \\
\hline$C_{o v}$ & - & Overlap coefficient \\
\hline$C_{s}$ & $\mathrm{Kg} / \mathrm{m}^{3}$ & Mass concentration \\
\hline$D_{a, \text { geo }}$ and $D_{p, \text { geo }}$ & $\mathrm{m}$ & Modal diameter of the aggregate and primary particles \\
\hline$D_{f}$ & - & Fractal dimension \\
\hline$D_{p b}$ & $\mathrm{~m}$ & Diameter of the primary sphere at the breakup \\
\hline$E(m)$ & - & Absorption function of the complex index of refraction \\
\hline$F(m)$ & - & Scattering function of the complex index of refraction \\
\hline$f(\vartheta)$ & - & Structure factor \\
\hline$f_{V}$ & - & Volume fraction \\
\hline$G_{a}$ and $G_{p}$ & $1 / \mathrm{m}$ & $\begin{array}{l}\text { Pre-factors of the Guinier Regime for aggregates and primary } \\
\text { spheres }\end{array}$ \\
\hline$l_{e}$ & $\mathrm{~m}^{2}$ & Electron scattering factor \\
\hline$k$ & $1 / \mathrm{m}$ & Wave number \\
\hline$k_{f}$ & - & Fractal pre-factor \\
\hline$k_{m}$ & $1 / \mathrm{s}$ & Mass based reaction rate \\
\hline$m$ & - & Complex index of refraction \\
\hline$n$ & - & Indicator of oxidation regime \\
\hline$N_{a g g}$ and $N_{d p}$ & $1 / \mathrm{m}^{3}$ & Aggregates and primary spheres number densities \\
\hline$N_{p}$ & - & Number of primary spheres per aggregate \\
\hline$p$ & - & Porod exponent \\
\hline$P D I_{a}$ and $P D I_{p}$ & - & Polydisperse indices for aggregates and primary spheres \\
\hline$q$ & $1 / \mathrm{m}$ & Magnitude of the scattering wave vector \\
\hline$R_{a, \text { geo }}$ and $R_{p, \text { geo }}$ & $\mathrm{m}$ & Modal radius of the aggregate and primary particles \\
\hline$R_{g a}$ and $R_{g p}$ & $\mathrm{~m}$ & Median radius of gyration of the aggregate and primary spheres \\
\hline$R_{p}$ & $\mathrm{~m}$ & Radius of the primary sphere \\
\hline$\rho_{p}$ & $\mathrm{Kg} / \mathrm{m}^{3}$ & Bulk density (density of the primary sphere) \\
\hline$S_{p}$ & $\mathrm{~m}^{2}$ & Surface area of a primary sphere \\
\hline$T$ & $\mathrm{~K}$ & Temperature of the surrounding gas \\
\hline$\tau$ & s & Characteristic time of the mass reduction process \\
\hline$t$ & s & Time \\
\hline
\end{tabular}




\begin{tabular}{|l|c|l|}
$T_{\text {inc }}$ & $\mathrm{Kg} / \mathrm{m}^{3}$ & Temperature of incandescence of the LII signal \\
\hline$t_{\text {res }}$ & $\mathrm{s}$ & Residence time \\
\hline$V_{a}$ and $V_{p}$ & $\mathrm{~m}^{3}$ & Volume of an aggregate and of a primary sphere \\
\hline$W$ & $\mathrm{~g} / \mathrm{cm}^{2} / \mathrm{s}$ & Specific soot burnout rate \\
\hline$x_{p}$ & - & Size parameter \\
\hline$z$ & $\mathrm{~m}$ & Height above the burner (HAB) \\
\hline & & \\
\hline$\theta$ & $\mathrm{rad}$ & Scattering angle \\
\hline$\lambda$ & $\mathrm{m}$ & Wavelength \\
\hline$\lambda_{\text {det }}$ & $\mathrm{m}$ & Detection wavelength of the LII signal \\
\hline$\rho_{e}$ & $1 / \mathrm{m}^{3}$ & Electron density \\
\hline$\sigma_{a, g e o}$ and $\sigma_{p, \text { geo }}$ & - & $\begin{array}{l}\text { Geometric standard deviation of the aggregates and primary } \\
\text { sphere size }\end{array}$ \\
\hline
\end{tabular}

\section{INTRODUCTION}

Soot emissions from combustion processes have important environmental and health consequences and so the characterization of soot particles and their formation mechanisms are subjects of ongoing research [1-3]. Soot oxidation [4-7] is a key process in the elimination of soot nanoparticles produced during the combustion and the proper control of oxidation, by for example using optimized fuel/air ratios and ensuring proper mixing, is essential in reducing automobile, aircraft and marine engine emissions.

Most of the experimental studies related to the oxidation of soot particles are ex-situ, based on the study of the behavior of deposited materials heated in furnaces [8-12]. If these investigations are of interest for the optimization of different catalytic processes including the regeneration of particulate filters [13], they do not yield information on the physical processes involved in the oxidation of soot particles under flame conditions where the $\mathrm{OH}$ radical is a major oxidative species and can dominate the role played by $\mathrm{O}_{2}[14,15]$. However, the reduction of soot particle emissions from different combustion systems can also be envisaged by an optimization of the combustion process itself. Numerical modeling is a promising tool to optimize combustors; nevertheless, the main mechanisms involved in soot formation (mainly surface growth and oxidation) need to be better understood [16]. Even if $\mathrm{O}_{2}$ and $\mathrm{OH}$ are considered to be the most oxidizing species, the role played by each one is not 
yet perfectly understood $[14,17,18]$. It is generally admitted that $\mathrm{OH}$ is more reactive than $\mathrm{O}_{2}$ thus more likely to react on the soot particle surface, while $\mathrm{O}_{2}$ can penetrate further into the particles, favoring their internal burning [18-20]. The depth in the attacked particle is not known nor is the precise mechanism producing the aggregate fragmentation (rupture of the necking between primary spheres or internal burning) [20-23]. Indeed, the precise mechanisms for reactions at the particle surface are not clearly understood either [24]. For these reasons, many studies have been performed in flames to characterize the oxidation process using ex-situ techniques [10-12, 20, 22, 25-28] or in-situ optical techniques $[15,18,19,29-32]$ generally based on laser light extinction, scattering and the depolarization ratio.

Most of these studies, however, cannot isolate oxidation from surface growth processes occurring within sooting flames. One interesting way to overcome this drawback and to focus on the oxidation process in isolation, is to inject previously produced soot particles into a non-sooting flame (i.e. a "two stage burner") as previously performed by Neoh, et al. [19], Echavarria, et al. [20] and very recently by Ghiassi, et al. [28] and Sirignano, et al. [33]. Indeed, in this case, the behavior of the soot particles is not representative of natural flames, nevertheless, it allows the oxidation process to be isolated from surface growth occurring simultaneously, for a better understanding of the soot life-cycle. The final aim of such experiments is to be able to produce accurate oxidation models for numerical soot formation codes.

With the exception of Neoh et al., however, all this work was ex-situ involving the sampling of the particles. Neoh, et al. [19] performed optical and in-situ measurements on a two-stage burner by coupling light scattering and extinction but their results were based on Mie theory, thus considering soot as spherical particles. Unfortunately, it has been shown that Mie theory is not relevant for fractal aggregates [31, 34]. Moreover, the use of visible light does not allow the very small scales to be investigated which are typical of those of the primary spheres (around $30 \mathrm{~nm}$ ).

Small Angle X-ray Scattering (SAXS) is a technique which can provide information on the size and shape of nanoparticles in the range of a few to tens of nanometers. This technique has already been 
used for the in-situ characterization of soot [35-40] but these studies were not focused on the specific examination of the oxidation process. Nevertheless, most of the SAXS experiments performed up until now, do not yield information concerning primary particle diameter and aggregate size to be obtained at the same time, when the latter exceeds $100 \mathrm{~nm}$. This information can be obtained by means of complementary measurements based on visible Static Light Scattering (SLS). Another powerful optical and in-situ technique for characterizing the local soot volume fraction in flames, is Laser Induced Incandescence (LII) [41] and for these reasons, the current work has combined SAXS, SLS and LII for the characterization of the oxidation of soot particles in a two-stage burner.

The main improvement in terms of diagnostics used in comparison with the work of Neoh, et al. [19] is the coupling of three complementary techniques and the use of an optical model, dedicated to fractal aggregates. Using these three techniques, the primary particle size distribution, number density, aggregate size, soot volume fraction and surface area can be determined in a single study. The impact of oxidation on the primary sphere internal microstructure cannot be investigated by these techniques; nevertheless, this aspect has already been examined in previous studies [9, 42-44].

\section{EXPERIMENTAL APPARATUS}

In the present experiment, the two-stage burning strategy is achieved by injecting well controlled and characterized soot particles into the centerline of a non-sooting, premixed flame. The experimental arrangement is shown in Fig. 1. Soot is first produced by a miniCAST burner. A thermodenuder (TSI 3065) is used to ensure that volatile species will not condense onto the soot particles after their generation before their injection into a non-sooting flame. A modified version of the McKenna burner with a central tube is used in order to make possible the injection of the soot into the centerline of a non-sooting premixed flame. This strategy has already been used in order to inject gases [45], metal catalyst precursors [46], or different sprays [47] into flames. The McKenna burner presents the advantage of generating stable 1D flames favoring their modelling.

A bypass allows either soot and its surrounding gas to be delivered into the center of a McKenna burner or only the surrounding gas by removing the soot particles by means of a high-efficiency filter (MSA Safety). This procedure was used for the subtraction of the background signal for SAXS 
measurements. The composition of this surrounding gas has been determined using a Testo 350 Portable Emissions Analyzer. It was shown to contain 8\% O2, 1.6\% CO2 and 146 ppm of CO. Once injected into the non-sooting flame (described below), a progressive reaction of the aerosol with the surrounding flame occurs. It results in an increase of the soot temperature causing a thermal emission (yellow part of the flame shown in Fig. 1-A) and, simultaneously, oxidation of the soot particles. In order to gain a qualitative idea on which reactive species soot were exposed to during their travel through the flame, a numerical evaluation of the main oxidizing species along the central axis of the burner is achieved using Chemkin software (see supplementary material 2). The corresponding results are integrated into section 4.4 .

The burner was positioned on a 3-axis movable table allowing the optical measurements to be performed at different heights above the burner (HAB). In addition to the SAXS experiment, a Nd:YAG laser was used for the LII and SLS measurements (Fig. 1-B), described below.

\subsection{SOOT GENERATION AND ITS CHARACTERIZATION}

A commercial miniCAST generator (model 5206, Jing Ltd.) was used to generate soot particles under stable and repeatable operating conditions. For more information concerning the characterization of the soot produced by the miniCAST and the operation of this burner, please refer to [48]. The selected operating condition was as in $[49,50]$ but the dilution air was turned off in order to increase the particle concentration for the SAXS experiments. The corresponding characteristics of the generated particles are reported in Table 1. Except for size distribution and volume fraction, that have been measured for the present experiment, other characteristics (marked with a superscript asterisk in Table 1) are not considered to be affected by the dilution air since nitrogen quenching is performed upstream. The size distribution of the generated soot particles was determined using a Scanning Mobility Particle Sizer (SMPS) (TSI 3080). It was found to be log-normal, the corresponding modal diameter, geometric standard deviation and number concentration being reported in Table 1. Note that reported values were corrected with a dilution of (1:100) produced by a PALAS VKL dilution system, in order to avoid the saturation of the SMPS. A model based on [49], was applied for the conversion of the size distribution based on mobility diameter to the size distribution based on gyration diameter. 
The corresponding modal diameter and geometric standard deviation are marked in Table 1 with indices ${ }^{* *}$. In addition, the volume fraction of the generated particles was determined using a Pegasor Particle Sensor (PPS), initially calibrated for the miniCAST operating condition using a TEOM (R\&P 1105) ambient particulate monitor. Finally, the organic content (OC/TC ratio) was determined using a SUNSET LAB thermoanalyzer with the IMPROVE_A protocol.

\subsection{Small Angle X-Ray Scattering}

The SAXS experiments were performed in June 2015 on the SWING beamline at the SOLEIL synchrotron in France. A $12 \mathrm{keV}(1 \AA)$ collimated, monochromatic X-ray beam $\left(40 \times 250 \mu \mathrm{m}^{2}\right)$ was used and the distance between the detector and the flame was set at $1.7 \mathrm{~m}$ corresponding to an analysis in the domain $0.006<q<0.05\left(\AA^{-1}\right)$, where $q=(4 \pi / \lambda) \sin (\theta / 2)$, with $\lambda$ and $\theta$ being the wavelength of the incident radiation and the scattering angle respectively. Considering that $D \sim \pi / \lambda$, this range corresponds to particles of between 6 and $50 \mathrm{~nm}$.

Table 1. Operating conditions and properties of particles produced with the miniCAST. Values reported (*) have been determined in [50] and conversion of the aggregate size distribution into gyration diameter $\left(^{* *}\right)$ is based on the model developed in [49].

\begin{tabular}{|c|c|c|}
\hline \multirow{4}{*}{$\begin{array}{c}\text { CAST } \\
\text { operating } \\
\text { conditions }\end{array}$} & Propane $\left(\mathrm{ml}_{\mathrm{n}} / \mathrm{min}\right)$ & 60 \\
\hline & Nitrogen $\left(\mathrm{ml}_{\mathrm{n}} / \mathrm{min}\right)$ & 0 \\
\hline & Oxidation air $\left(\mathrm{l}_{\mathrm{n}} / \mathrm{min}\right)$ & 1.5 \\
\hline & Dilution air $\left(\mathrm{l}_{\mathrm{n}} / \mathrm{min}\right)$ & 0 \\
\hline Transmission & Primary sphere modal diameter $(\mathrm{nm})^{*}$ & 26.6 \\
\hline \multirow{3}{*}{$\begin{array}{c}\text { Electron } \\
\text { Microscopy } \\
\text { (TEM) }\end{array}$} & $\begin{array}{l}\text { Standard deviation of the log-normal } \\
\text { primary sphere diameter size distribution } \\
\qquad(\mathrm{nm})^{*}\end{array}$ & 1.31 \\
\hline & Fractal dimension $(-)^{*}$ & 1.73 \\
\hline & Fractal pre-factor $(-)^{*}$ & 1.94 \\
\hline \multirow{3}{*}{ SMPS } & Modal mobility diameter (nm) & 157 \\
\hline & Modal gyration diameter $(\mathrm{nm})^{* *}$ & 222 \\
\hline & $\begin{array}{l}\text { Geometric mobility } \\
\text { standard deviation (-) }\end{array}$ & 1.57 \\
\hline
\end{tabular}




\begin{tabular}{|c|c|c|}
\hline \multirow{2}{*}{} & $\begin{array}{c}\text { Geometric gyration } \\
\text { standard deviation }(-)^{* *}\end{array}$ & 1.9 \\
\cline { 2 - 3 } & Number concentration $\left(\times 10^{13} \mathrm{part} / \mathrm{m}^{3}\right)$ & 3.65 \\
\hline Effective density & Density $\left(\mathrm{kg} / \mathrm{m}^{3}\right)^{*}$ & 1543 \\
\hline PPS & Volume fraction (ppb) & 27.2 \\
\hline \multirow{2}{*}{ Thermoanalysis } & OC/TC (\%) ${ }^{*}$ & 4.1 \\
\cline { 2 - 3 } & OC/EC (\%) (based on OC/TC) & 4.3 \\
\hline
\end{tabular}

\subsection{LASER INDUCED INCANDESCENCE (LII) AND STATIC LIGHT SCATTERING (SLS)}

A Q-switched Nd:YAG (Quantel Brilliant EaZy) with a pulse width of $5 \mathrm{~ns}$ FWHM operated at $10 \mathrm{~Hz}$ was used for these measurements. Laser fluence was controlled with a beam attenuator module coupled with a power meter (Gentec Maestro). A half-wave plate was used to obtain a fixed vertical polarization state (orthogonal to the scattering plane) for all the experiments. Two excitation wavelengths were available depending on the type of measurement. For LII measurements, the first harmonic (1064 nm) was used as the exciting wavelength. For SLS measurements, the second harmonic $(532 \mathrm{~nm})$ was generated using a doubler module $(2 \omega)$. To obtain a beam with a more uniform energy distribution, a rectangular top-hat profile was generated using a 1-mm rectangular aperture coupled with a lens with a focal length of $35 \mathrm{~cm}$ (L1 in Fig. 1-B). A beam analyzer (Photon USBeamPro CCD) was used to ensure similar laser beam profiles for both excitation wavelengths (supplementary material Fig. S1); this correspondence was accomplished by adjusting the position of the $L 1$ lens (profiles not presented). The laser beam had a diameter of $1.8 \mathrm{~mm}$ at the center location of the hybrid McKenna burner. For both excitation wavelengths, the laser fluence was set at $0.2 \mathrm{~J} / \mathrm{cm}^{2}$, so as to preventing any sublimation of the soot particles (supplementary material 1, Fig. S2 and S3).

\section{|||||||||||||||||||||||||||||//Figure 1//I/|||||||||||||||||||||||||||}

Signals were collected using two identical optical paths (Fig. 1-B) consisting of a polarizer (in the vertical position), two lenses (focal lengths of $L 2=L 2^{\prime}=20 \mathrm{~cm}$ and $L 3=L 3^{\prime}=10 \mathrm{~cm}$ ), a $1 \mathrm{~mm}$ pinhole, a bandpass filter ( $\lambda_{d e}=532 \mathrm{~nm}$ for SLS and $442 \mathrm{~nm}$ for LII at $10 \mathrm{~nm}$ FWHM), and a 
photomultiplier (PM, Hamamatsu H3378-50). The first arm was positioned at $90^{\circ}$ for LII measurements and at $33^{\circ}$ for the SLS measurements. An oscilloscope (LeCroy WavePro 725Zi 2.5 $\mathrm{GHz}$ ) was used for signal acquisition. Each measurement represented an average of 200 measurements, thereby allowing uncertainties to be evaluated.

\subsection{THE OXIDIZING FLAME}

The non-sooting flame was generated by a hybrid McKenna burner (Fig. 1-A) enabling the central injection of gases or particles. The premixed air/propane flame was held on a porous bronze plate with a diameter of $60 \mathrm{~mm}$ with a flow rate of $36.23 \mathrm{l}_{\mathrm{n}} / \mathrm{min}$ for air and of $1.522 \mathrm{l}_{\mathrm{n}} / \mathrm{min}$ for propane corresponding to a stoichiometric flame. The flame was stabilized using an external air-flow ring. The aerosol was injected into the center tube (6 mm diameter) of the burner at a flow rate of $0.63 \mathrm{l} / \mathrm{min}$ (measured with a Gilibrator-2 Calibration System from Sensidyne). The temperature of the porous plate was regulated by oil circulation maintained at $16^{\circ} \mathrm{C}$.

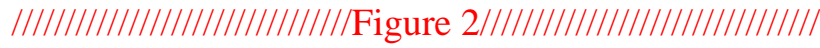

The vertical temperature profile (Fig. 2-A) of the flame was determined by inserting a type B thermocouple at different heights above the burner. Note that measurements were performed without soot injection into the non-sooting flame. Hence, the measurements were not affected by soot deposition on the thermocouple and by the radiation from these particles. Nevertheless, the radiation of the thermocouple had to be taken into account by determining the convective heat transfer and the emissivity of the thermocouple based expressions respectively and the formulae reported in [51] and [52]. The expression of the fitted curve (dashed red line in Fig. 2-A) is given in Equation (1).

$T=915 \times\left(1+\operatorname{erf}\left(\frac{z \times 100-1.18}{1.88}\right)\right)$ with $z$ the HAB expressed in meter and $T$ in ${ }^{\circ} \mathrm{K}$.

The residence time in the flame was determined using particle vaporization velocimetry [53]. This technique consists in using a high laser fluence in order to instantaneously vaporize the soot particles. The "hole" in the flame so formed, is shifted in time at the local velocity of the flame. This velocity is then determined by imaging the flame with an image intensified camera with and without applying a temporal offset (2 ms). In order to enhance the detection in this experiment, the central injection of the 
miniCAST aerosol flow-rate was reduced to $0.6 \mathrm{l} / \mathrm{min}$ and enriched with $30 \mathrm{ml} / \mathrm{min}$ of propane in order to enhance the generation of soot at the center of the burner. The obtained velocities are reported in Figure 2-B (black filled squares). Unfortunately, the natural emission of soot was too low at the bottom of the flame (i.e. for HAB lower than $30 \mathrm{~mm}$ ) and the technique was no longer practical at these low HAB distances. The observed linear tendency of the flame velocity versus HAB was then extrapolated down to $\mathrm{HAB}=0 \mathrm{~mm}$ (black dashed curve in Fig. 2-B) showing good agreement with the aerosol injection velocity at the center of the McKenna burner (blue diamond) and with the numerical evaluation performed using Chemkin up to $\mathrm{HAB}=30 \mathrm{~mm}$ (see Supplementary material 2). The integration of this linear tendency allows the residence time (red plain curve) to be evaluated, corresponding to the Eq. (2):

$t_{\text {res }}=\frac{1}{a} \ln \left(\frac{a}{b} z+1\right)$ based on $v=a x+b$ with $a=42.76 \mathrm{~s}^{-1}, b=0.37 \mathrm{~m} / \mathrm{s}$

$z$ represents the HAB expressed in meter and $t_{r e s}$ in second. For lower HAB, that extrapolation is in very good agreement with the Chemkin evaluation of the residence time. For higher HAB (not reported in Fig. 2), the Chemkin results over-predict the residence time due to the limitation of the 1D hypotheses at these large distances. The values obtained are also comparable with values measured by Xu et al. [32] in a premixed ethylene/air flame with a McKenna burner as well as values computed by Kong et al. [54] for a methane/air flame.

\section{Preliminary Results}

Two vertical scans of the flame were performed, first with injection of the soot particles and second with a prior filtering of the particles (High Efficiency Particle Filter, see Fig. 1). The second measurement was subtracted from the former one in order to isolate the contribution from soot alone. In Figure 3-A we present the results obtained with the SAXS experiment. As expected, the signal decreased with the height above the burner suggesting a decrease of soot mass concentration within the flame due to the oxidation process. In this representation of the data, however, there is no clear evidence of a decrease of the particle size nor of a change of surface roughness. Figure 3-B represents the same results by means of a Porod plot i.e. the signal is multiplied by $q^{4}$ and plotted $v s q$. Indeed, for smooth spheres, with a sharp interface with the surrounding medium, the signal intensity will 
decrease as $q^{-4}$ at large $q$ and so, in this case, the Porod plot will present a plateau, parallel to the abscissa. Despite the increasing uncertainty related to the decreasing of the signal-to-noise ratio, this plateau is well observed indicating that primary spheres keep presenting a smooth interface during the oxidation process, contrarily to oxidation of metallic nanoparticles, studied in a recent experiment [55] that presented a more rugged surface in the presence of a high oxygen concentration atmosphere. Moreover, we also observed a progressive shift of the plateau to the larger $q$ parameter as the HAB increased. This is a first qualitative indication that primary particle size decreases during the oxidation process.

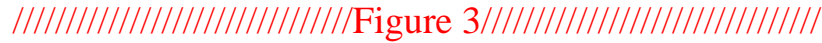

In Figure 4, the maximum of the LII signal as a function of the HAB is shown as solid black circles in the upper panel. As with the SAXS measurements, this signal is seen to decrease with HAB suggesting a decrease of the soot volume fraction. Nevertheless, even if the LII signal is often considered to be proportional to the volume fraction, as will be explained further in the analysis section, a significant change of the local temperature as well as a change of soot primary particle, may also influence the LII signal. We will show that taking these effects into account yields the red empty circles in the upper panel of Fig. 4.

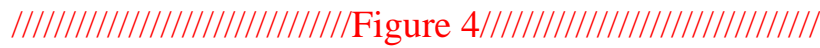

The lower panel of Fig. 4 presents the decrease of the scattered light collected at a $33^{\circ}$ scattering angle. The error bars highlight the uncertainty of the results at HABs larger than $20 \mathrm{~mm}$. In the remainder of the document, the fitted (black dashed curve) will be considered.

\section{ANALYSIS}

In this section, we present the methodology used for the interpretation of the results presented in the previous section in terms of the evolution of soot volume fraction, primary particle size, aggregate size and number density during the oxidation process. 


\subsection{MODELING OF THE LIGHT SCATTERING DATA (SAXS AND SLS)}

When photons elastically interact with matter, most are forward scattered but some are scattered into other angles. When a flux of photons is collected at a given scattering angle $\theta$, its intensity is affected due to the interferences occurring by summing electromagnetic radiations coming from different locations of the particles, leading to optical path differences. Consequently, the angular dependence of the scattered intensity is a marker of the particle size and shape. Whether for SAXS or SLS, the phenomena are similar and it is generally preferred to interpret the signals as a function of the magnitude of the scattering wave vector $q=\frac{4 \pi}{\lambda} \sin \left(\frac{\theta}{2}\right)$ instead of using the scattering angle $\theta$. The inverse of $q$ is an order of magnitude of the sensitivity of the measurement technique to the particle size [56]. It is clear therefore that SLS and SAXS, based respectively on visible and X-ray photons, will probe soot particles at different and complementary size scales. More precisely, hard X-ray SAXS is typically used for particles whose size is between a few $\mathrm{nm}$ up to about one hundred nanometers whereas SLS will cover sizes between 50 and $500 \mathrm{~nm}$. Consequently, for soot particles, the former technique will have particular relevance for the description of the primary spheres whereas the latter will be appropriate for the description of the aggregate size.

When the signals are integrated over a large population of isotropically oriented particles, the scattering pattern is generally smooth and can be interpreted by asymptotic theories. For soot particles, SLS angular measurements are generally interpreted with the help of the Rayleigh Debye-Gans Theory for Fractal Aggregates (RDG-FA) introduced by Dobbins and Megaridis [34] and used by many researchers [57-60]. The reader can refer to the review by Sorensen [61] on this theory. We shall retain the generalized expression of the Dobbins and Megaridis expression of the scattered signal for a vertical-vertical polarization:

$$
\begin{array}{ll}
S L S_{v v}^{\text {theo }}(\theta) \propto N_{a g g} \frac{x_{p}^{6}}{k^{2}} F(m) \overline{N_{p}^{2} f(\theta)} & \\
f\left(q R_{g a}, D_{f}\right)=A \exp \left(-\frac{B}{3}\left(q R_{g a}\right)^{2}\right) & \text { if }\left(q R_{g a}\right)^{2}<\frac{3 C}{2 B} \text { (Guinier regime) } \\
f\left(q R_{g a}, D_{f}\right)=A\left(\frac{3 C}{2 B e} \frac{1}{\left(q R_{g a}\right)^{2}}\right)^{\frac{C}{2}} & \text { if }\left(q R_{g a}\right)^{2} \geq \frac{3 C}{2 B} \text { (power-law regime) }
\end{array}
$$


In Equation (3), $N_{a g g}$ is the aggregate number concentration, $x_{p}=\frac{\pi D_{p}}{\lambda}$ is the size parameter related to the primary particle size, $k=\frac{2 \pi}{\lambda}$ is the wave number, $F(m)=\left|\frac{m^{2}-1}{m^{2}+2}\right|^{2}$ is the scattering function depending on the complex index of refraction $m$ and $\overline{N_{p}^{2} f}$ is an arithmetic mean of the product between the number of primary spheres in the aggregate $N_{p}$ and the structure factor $f$. The structure factor $f$ reported in Eq. (3) is decomposed into two parts, the Guinier regime that represents the forward diffraction pattern dependent on the aggregate size expressed in terms of the radius of gyration $R_{g a}$ and the power law regime for larger scattering angles which tends to an asymptotic angular dependence of the form $q^{-C}$. In classical RDG-FA theory, $A=B=1$ and $C=D_{f}$ the fractal dimension of the aggregates, related to the well-known fractal law (Eq. (4)), with $k_{f}$ the fractal prefactor and $R_{p}$ the primary sphere radius).

$$
N_{p}=k_{f}\left(R_{g a} / R_{p}\right)^{D_{f}}
$$

Recent improvements of the RDG-FA theory, from our group [62], have shown that multiple scattering effects in the aggregates could lead to $A \neq B \neq 1$ and $C \neq D_{f}$.

The RDG-FA given in Eq. (3) is dedicated to visible scattering experiments and, for this reason, this theory is focused on the scale of the aggregate size $\left(R_{g a}\right)$. For SAXS experiments, Beaucage [63] introduced a similar approach to the RDG-FA, considering (Guinier and power-law regimes) for as many scales as necessary for the description of the SAXS measurements. For soot aggregates, the SAXS signal is a priori dominated by two length scales related to the aggregate size $R_{g a}$ and to the primary particle gyration radius $R_{g p}$. Thus, the collected signal can be modeled by the addition of two Guinier-Power law regimes, involving 8 parameters: 


$$
\begin{gathered}
\text { SAXS } S^{\text {theo }}=\underbrace{G_{a} \exp \left(-\frac{q^{2} R_{g a}^{2}}{3}\right)}_{S 1}+\underbrace{B_{a}\left(\frac{\left.\operatorname{erf}\left(\frac{q R_{g a}}{6^{0.5}}\right)\right]^{3 D_{f}}}{q^{D_{f}}}\right) \exp \left(-\frac{q^{2} R_{g p}^{2}}{3}\right)}_{S 2}+\underbrace{G_{p} \exp \left(-\frac{q^{2} R_{g p}^{2}}{3}\right)}_{S 3} \\
+\underbrace{B_{p}(\underbrace{\left(\frac{\left.\operatorname{erf}\left(\frac{q R_{g p}}{6^{0.5}}\right)\right]^{3 p}}{q^{p}}\right)}_{q^{p}}}_{S 4}
\end{gathered}
$$

The first two terms are related to the aggregates size (the power law is then driven by the fractal dimension $D_{f}$ ) and the two last terms to the primary particle size (fractal dimension is replaced by the Porod exponent $p$ related to the surface character of the primary spheres). Note that SAXS presents an advantage over SLS in that it does not depend on the complex index of refraction being known due to the fact that $m$ tends towards 1 at very low wavelengths and also multiple scattering effects are negligible.

The pre-factor $G_{a}=N_{a g g}\left(\rho_{e} V_{a}\right)^{2} I_{e}$ is related to the number density of aggregates, to the scattering contrast $\rho_{e}$ (electron density of the material), to $I_{e}=r_{e}^{2}$ the scattering factor of one electron (the square of the electron radius $r_{e}=2.818 \times 10^{-15} \mathrm{~m}$ ) and $V_{a}$ the aggregate volume. The same approach remains valid at the scale dominated by the primary spheres. The pre-factor $G_{p}=N_{d p}\left(\rho_{e} V_{p}\right)^{2} I_{e}$ is then related to the number density of primary spheres with $V_{p}$, the mean volume of the primary spheres. Due to the relations $N_{d p}=\overline{N_{p}} \times N_{a g g}, V_{a}=\overline{N_{p}} \times \overline{V_{p}}$ and because the volume fraction allows the aggregate number density to be related to the mean number of primary spheres per aggregate $\left(f_{V}=N_{a g g} \overline{N_{p}} \overline{V_{p}}\right)$, it becomes possible to link the two prefactors $G_{a}$ and $G_{b}$ Eq. (6).

$$
\begin{gathered}
G_{a}=\overline{N_{p}} \times G_{p} \\
G_{p}=f_{V} \overline{V_{p}} \rho_{e}^{2} I_{e}
\end{gathered}
$$

For spheres, the second pre-factor $B_{p}=2 \pi N_{d p} \rho_{e}^{2} S_{p}$ is related to the primary spheres surface area and to the primary sphere polydispersity index $P D I_{p}$ :

$$
P D I_{p}=\frac{B_{p} R_{g p}^{4}}{1.62 G_{p}} ; P D I_{a}=\frac{B_{a} R_{g a}^{D_{f}}}{G_{a}}
$$


The polydispersity index is equal to 1 for monodisperse particles and tends toward 5.56 in the case of a lognormal / self-preserving limit. $B_{a}$ can also be associated to a polydispersity index but, in order to be dimensionless, the gyration radius is raised to the power $D_{f}$ (Eq. (7)).

By considering lognormal distributions for primary spheres, the corresponding governing parameters (the geometric mean radius $R_{p, g e o}$ and the geometric standard deviation $\sigma_{p, g e o}$ respectively) are related to $R_{g p}$ and $P D I_{p}$ by the following relations [64, 65]:

$R_{p, \text { geo }}=R_{p}\left(\frac{5}{3} \exp \left(-14 \ln \left(\sigma_{p, g e o}\right)^{2}\right)\right)^{1 / 2}$ and $\sigma_{p, g e o}=\exp \left(\sqrt{\frac{\ln \left(P D I_{p}\right)}{12}}\right)$

Additionally, different moments (to order $n$ ) based on the size distribution of the primary spheres, can be determined by means of the Hatch-Choate equation:

$$
\overline{R_{p}^{n}}=R_{p, g e o}^{n} \exp \left(n^{2} \times \frac{\left(\ln \left(\sigma_{p, g e o}\right)\right)^{2}}{2}\right)
$$

This can be used for example for the determination of the mean volume of the primary spheres: $\overline{V_{p}}=$ $4 \pi \overline{R_{p}^{3}} / 3$

Finally, by combining Equations (4-9), it can be shown that the modeling of the SAXS signal for soot fractal aggregates, can be reduced to the following set of parameters: $\overline{N_{p}}, D_{p, g e o}, \sigma_{p, g e o}, f_{V}, D_{f}, P D I_{a}, \rho_{e}, I_{e}$ and $p$. Some of these parameters can be fixed. For example, Fig. 3-B shows that the Porod exponent remains equal to 4 , and $\rho_{e}$ and $I_{e}$ can be found in the literature.

Figure 5 presents such a modeling and extrapolation of the SAXS signal measured at $\mathrm{HAB}=2 \mathrm{~mm}$ in the oxidizing flame. The different terms appearing in Equation (5) are represented by different colored continuous lines in Fig. 5. It clearly appears that the SAXS measurements made during this campaign, were not sensitive to the aggregate size (this was because of the limited detection range, mentioned in 2.2 above). Only the $S 3$ and $S 4$ terms (driven by parameters $D_{p, g e o}, \sigma_{p, g e o}$ and $f_{V}$ ) are really constrained by the experimental data during the model adjustment. This is mainly due to the large size of the miniCAST soot injected at the center of the burner, confirming incidentally, the need for the 
complementary SLS measurements. In other terms, in the present study, the Beaucage model could have been reduced to only one scale analysis ( $S 3$ and $S 4$ terms) and other parameters related to $S 1$ and $\left.S 2 \overline{\left(N_{p}\right.}, D_{f}, P D I_{a}\right)$ are finally not constrained by the modelling of the SAXS experimental results. Consequently, the fractal properties can be considered constant and equal to the value reported in Table 1) as well as the $P D I_{a}$ parameter. For polymer coil particles with fractal dimension equal to 2 , Beaucage [63] found $P D I_{a}=2$. This value will also be considered in this work since the soot fractal dimension is not far from 2.

Consequently, only $\overline{N_{p}}, D_{p, g e o}, \sigma_{p, g e o}$ and $f_{V}$ become necessary for the theoretical evaluation of the measured SAXS signals.

|||||||||||||||||||||||||||||//Figure 5//I||||||||||||||||||||||||||||

\subsection{EXPLOITATION OF THE LII SIGNAL}

LII is an in-situ optical technique usually used to determine the soot volume fraction [41]. An intense laser source is used to heat the soot particles leading to a strong emission of radiation. This radiation is collected and interpreted as black body radiation. The intensity of this radiation can be directly linked to the local soot volume fraction [41]:

$$
L I I \propto f_{V} \frac{E\left(m, \lambda_{\text {det }}\right)}{\lambda_{\text {det }}{ }^{6}}\left(\exp \left(\frac{C_{2}}{\lambda_{\text {det }} T_{\text {inc }}}\right)-1\right)^{-1} \Delta \lambda_{\text {det }}
$$

In Eq. (10), $E(m, \lambda)=-\operatorname{Im}\left(\frac{m^{2}-1}{m^{2}+2}\right)$ is the absorption function, $\lambda_{\text {det }}$ the detection wavelengths of the LII signal, $T_{\text {inc }}$ the temperature of the incandescent soot particles and $\Delta \lambda$ det the bandpass filter wavelength width. Nevertheless, the LII signal is also strongly dependent on the incandescent soot temperature caused by the laser heating. In the present study, the incandescent temperature of the flame depends on the local initial temperature of the flame (Fig. 2-A) and on the heating produced by the laser beam exposure. This temperature behavior is modeled by solving the following equations inspired by the review [66] and the reader is invited to refer to this paper for a detailed explanation of these equations: 


$$
\begin{gathered}
\frac{d M}{d t}=-\frac{\pi D_{p}^{2} W_{v} \alpha M p_{v}}{R_{p} T} \sqrt{\frac{R T}{2 W_{v}}} \\
\underbrace{\rho c_{p} \frac{\pi}{6} D_{p}^{3}(t) \frac{d T}{d t}}_{\text {heating }}=\underbrace{\frac{\pi^{2} D_{p}^{3} E(m)}{\lambda_{\text {laser }}} F(t)}_{\text {absorption }}-\underbrace{\frac{2 K_{a} \pi D_{p}^{2}}{D_{p}(t)+G l p m}(T-T 0)}_{\text {conduction }}-\underbrace{\frac{199 \pi^{3} D_{p}^{3}(t) k_{b}^{5} E(m)}{h(h)^{3}}\left(T^{5}-T_{0}^{5}\right)}_{\text {Radiation }}+\underbrace{\frac{\Delta H_{v}}{W_{s}} \frac{d M}{d t}}_{\text {Sublimation }}
\end{gathered}
$$

This system of differential equations can be solved for different heights above the burner by considering the local flame temperature (Fig. 2-A) and the local primary particle size diameter as initial conditions (determined by SAXS). The temporal behavior of the particle temperature so modeled is then used to determine the LII signal by using Eq. (10). Fig. 6 presents some results of this modeling for three heights above the burner. The upper part represents the temporal evolution of the primary particle diameter normalized by its initial value before injection into the burner. It can be seen that the diameter of the primary spheres does not vary significantly during the laser pulse (the sublimation process is not significant). On the other hand, the temperature profile (center part of Fig. 6) and consequently the LII temporal decay (bottom part of Fig. 6) are strongly dependent on the HAB due to the strong variation of the flame temperature. The modeled maximum of the LII signal is seen to appear earlier with increasing $\mathrm{HAB}$ due to the increase of the local temperature, the same decay is seen in the experimental LII data (not presented). The amplitude of the LII signal decreases with HAB due to the decrease of the soot volume fraction.

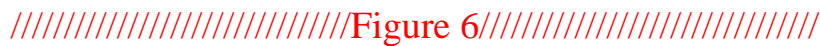

With this method, the local volume fraction is fitted in order to match the maximum modeled LII signal with the measured signal. Note that the volume fraction at $\mathrm{HAB}=0 \mathrm{~mm}$ is set to $27.2 \mathrm{ppb}$ in accordance with PPS measurements on cold soot (Table 1). Figure 4 shows the volume fraction profile obtained by applying this procedure, in red dots. The continuous red line is determined by an empirical fitting process according to the function:

$f_{V}=\frac{c}{z+d}$ with $c=0.134 \mathrm{~m}, d=4.735 \times 10^{-3} \mathrm{~m}, z$ the HAB expressed in $\mathrm{m}$ and $f_{V}$ expressed in ppb. 
This figure shows that not taking into account the local temperature and primary particle size, i.e. considering that the maximum of the LII signal is directly proportional to the volume fraction, tends to overestimate the local volume fraction.

\subsection{ANALYSIS BASED ON THE COUPLING OF SLSISAXS AND LII MEASUREMENTS}

As shown in the previous sections, the SAXS fitting with the Beaucage model implies seeking $\overline{N_{p}}, D_{p, g e o}, \sigma_{p, g e o}$ and $f_{V}$. We observed that the $q$-domain covered by SAXS is particularly suited for the determination of the primary particle size distribution parameters $\left(D_{p, g e o}, \sigma_{p, g e o}\right)$. On the other hand, for the current experiment and for the chosen target to detector distance used on the SWING beamline, the aggregate size could not be addressed (Fig. 5). Nevertheless, the size of the aggregates, here represented by the $\overline{N_{p}}$ parameter, is of prime interest for the modeling of the SLS signal. Indeed, from Eq. (3), it can easily be shown that the ratio between SLS signal and the volume fraction, depends directly on the aggregate size distribution:

$$
\frac{S L S_{v v}^{\text {theo }}}{f_{V}}=\alpha F(m) \frac{\overline{D_{p}^{6}}}{\overline{D_{p}^{3}}} \frac{\overline{N_{p}^{2} f(\theta)}}{\overline{N_{p}}}
$$

The moments based on the primary particle size distribution are determined using the Hatch-Choate equation (Eq. 9) based on SAXS results and those based on the number of primary spheres per aggregate are numerically computed, based on the assumption of log-normal size distributions for the gyration diameter $\left(D_{a, g e o}, \sigma_{a, g e o}\right)$ and structure factor reported in Eq. (3). Note that the fractal parameters and optical constants are considered to remain constant during the oxidation process as well as the geometric standard deviation of the aggregate size distribution based on the gyration diameter $\left(\sigma_{a, \text { geo }}=1.9\right.$, see Table 1$)$.

In addition, we have shown that LII is sensitive to the volume fraction $f_{V}$. Consequently, the proposed inversion process is to constrain the SAXS data fitting with the LII and SLS data. Indeed, for each HAB, the volume fraction is fixed by the LII measurement and $\overline{N_{p}}, D_{p, g e o}, \sigma_{p, g e o}$ are sought using a least-squares method in order to fit the SAXS (Eq. (5)) and SLS (Eq. (13)) results together. Since this procedure is not conventional, the Igor Pro based "IRENA" package [67], often employed in the 
literature, was not used in the present study. Instead, the fitting procedure has been coded in Scilab with the use of the Levenberg-Marquardt least-squares algorithm. Note that, because the volume fraction determination is dependent of the primary sphere diameter (see section above), an iteration procedure was used to converge (Fig. 7). Nevertheless, because the SAXS signal is very insensitive to the aggregate size, the conversion is reached with only two iterations.

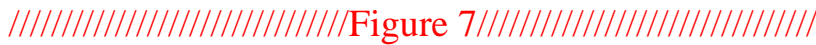

The unknown constant of proportionality $\alpha$, related to the light scattering measurement in Eq. (13), is determined in order that the inversion process yields $D_{a, g e o}=222 \mathrm{~nm}$ at $\mathrm{HAB}=2 \mathrm{~mm}$, based on the hypothesis of continuity of the aggregate size once injected into the oxidizing flame (value reported in Table 1 for the size distribution measured by SMPS, expressed as the gyration diameter).

\subsection{INTERPRETATION OF THE RESULTS}

By applying the previously described inversion process, the SAXS, SLS and LII measurements have allowed the aggregate size $\overline{N_{p}}$, the primary particle modal diameter $D_{p, g e o}$, the geometrical standard deviation $\sigma_{p, g e o}$ and the volume fraction $f_{V}$ (already presented in Fig. 4) to be determined. By using relations expressed in section 4.1, it is then possible to determine the aggregate and the primary sphere number densities (respectively $N_{a g g}$ and $N_{d p}$ ). Figure 5 is an example of the application of this fitting procedure for $\mathrm{HAB}=2 \mathrm{~mm}$. A first notable result is that the fitting procedure is very good except for $\mathrm{HAB}=10$ and $24 \mathrm{~mm}$ (see the Pearson's correlation coefficient represented by red crosses in Fig. 8). This indicates that volume fractions profiles derived from the LII measurements, are in very good agreement with SAXS signal amplitude. Indeed, we have previously shown (see Eq. (6)) that the amplitude of the SAXS signal ( $G_{a}$ and $G_{p}$ terms) is directly proportional to $f_{V}$. Nevertheless, for this to be possible, the electron density had to be fixed to $\rho_{e}=3.59 \times 10^{27} \mathrm{~m}^{-3}$ i.e. 190 times lower than value found in the literature for graphite [68]. This difference of magnitude cannot be explained by an uncertainty concerning the estimation of the volume fraction of soot produced by the miniCAST. It has already been reported that the electron density for soot particles is reduced compared to that of graphite due to their hydrogen content [69] or more generally to their molecular composition and 
resulting density [70]. It is worth noting that the currently proposed electron density is only 8 times lower than the total electron density deduced by fitting soot extinction spectra with Drude-Lorentz dispersion model for the same operating conditions of the miniCAST [50]. This observation indicates that a direct determination of soot volume fraction from SAXS data can suffer from a large uncertainty if measurements are interpreted on the basis of electron density of graphite since that parameter seems to be highly dependent on the real composition (mainly oxygen and hydrogen content) and microstructure of the material.

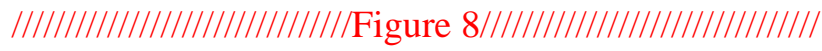

The results of the inversion process are reported in Fig. 8. In this figure, black filled boxes correspond to the evaluation of the parameters on cold soot by non-optical techniques (value reported or deduced from Tab. 1). For example, $D_{p, g e o}$ and $\sigma_{p, g e o}$ determined by the inversion process at $\mathrm{HAB}=2 \mathrm{~mm}$ are found to be in excellent agreement with the value determined by the automatized analysis of the TEM images (EDM-SBS analysis [71]). This is a performance indicator of the Beaucage model for polydisperse spheres (Eq. (5) and Eq. (7)). Error bars represent a 95\% interval confidence associated with the inversion process and based on the error propagation of the uncertainties related to the SAXS, LII and SLS data (standard deviation delivered by the SAXS software and bars reported in Fig. 4 for LII and SLS signals). Except for 2 HAB, for whom the scattered patterns are not conventional (see Fig. 3B) causing less good Pearson coefficients, it clearly appears that modal diameter of primary particles decreases with the oxidation process and that the geometric standard deviation increases.

As discussed above, the aggregate size determination is principally governed by SLS measured at a $33^{\circ}$ scattering angle and by the LII measurement (Eq. (13)). It must be noted that such an inversion is only possible when considering the multiple scattering corrections in Eq. (3). Indeed, at this scattering angle, for $\lambda=532 \mathrm{~nm}$, the theoretical ratio $\overline{N_{p}^{2} f(\theta)} / \overline{N_{p}}$ from classical RDG-FA theory, rapidly tends to a constant for large aggregates. Fortunately, the taking into account of multiple scattering effects in RDG-FA theory (that depends on the number of primary spheres and also on the primary particle size) enables the variation with HAB of the ratio of the SLS signal and the volume fraction to be 
interpreted. By considering such corrections, one can observe an unexpected rapid increase in aggregate size up to $\mathrm{HAB}=10 \mathrm{~mm}$. Aggregation is directly driven by the particle mobility and the mean free path of an aggregate is proportional to the temperature and inversely proportional to the particle mass and diameter. So, it seems that the decrease of the primary particle mass due to the oxidation process and the rapid increase of the temperature of the particles cause significant reaggregation once the soot is injected into the flame. However, for HABs larger than $18 \mathrm{~mm}$, the aggregate size (expressed as the number of primary spheres $N_{p}$ ) begins to decrease indicating that the fragmentation process starts to dominate over aggregation. At this $\mathrm{HAB}$, the primary particle diameter is reported to be $D_{p}^{b}=21,7 \mathrm{~nm}$, i.e. approximatively $20 \%$ smaller than before introduction into the flame $\left(D_{p 0}\right)$. By considering a surface limited oxidation process (discussed later), it can be considered that fragmentation should occur when connectivity between primary sphere is lost [23], i.e. when the primary sphere diameter overlap vanishes. The overlap coefficient is defined by $C_{o v}=\frac{D_{p}-d}{D_{p}}$ with $d$ representing the primary spheres center-to-center distance [72-74]. Thus, at breakup, $C_{o v}^{b}=\frac{D_{p}^{b}-d}{D_{p}^{b}}=0$ and consequently $d=D_{p}^{b}$. So, by considering $d$ constant during the oxidation process, the overlap coefficient before injection into the flame is considered to be $C_{o v}^{i n i}=\frac{D_{p 0}-D_{p}^{b}}{D_{p 0}}$ i.e. corresponding to the relative decrease of the primary sphere diameter at breakup, just evaluated to be $20 \%$. This result is in relative good agreement with the miniCAST soot particle overlap coefficient determined for the same operating conditions ( $C_{o v}=29 \%$ for miniCAST [74]). Consequently, in the present flame, it seems that particle fragmentation occurring at large HABs is dominated by the breaking of the bridge between primary spheres that could be related to a surface limited oxidation, generally attributed to $\mathrm{OH}$ radicals $[19,21,22]$. Note that it has also been observed that $\mathrm{O}_{2}$ could be surface limited as a function of soot maturity [23]. In the present study however, breakup appears for primary particles larger than the minimum size reported by Ghiassi, et al. [22] for $\mathrm{O}_{2}$ causing internal burning, reinforcing the assumption of oxidation dominated by $\mathrm{OH}$ attack in the present case.

By considering that evaluation of the aggregate size and other results, it becomes possible to evaluate the aggregate number density. This parameter first decreases due to the re-aggregation process and 
perhaps to the total oxidation of smaller particles. When the inverse of that density is plotted as a function of residence time (not shown), it appears that the re-aggregation process takes the form $N_{a g g}^{-1}(t)=9.17 \times 10^{-11} t^{1.25}$ for $t$ expressed in seconds and $N_{a g g}^{-1}$ in $\mathrm{m}^{3}$. This nonlinear dependence on residence time reveals a kinetic exponent of 1.25 which is typical of fractal aggregation in the intermediate continuum regime [75]. Nevertheless, the rate at which aggregate size increases during this stage, appears to be very high compared to the conventional rates encountered in the literature. This could be explained by the particularity of the present flame where only oxidation processes take place and there is no surface growth (see discussion above on soot mobility). The increase of the aggregate number density occurring for $\mathrm{HAB} \geq 18 \mathrm{~mm}$, probably due to the fragmentation process, is in good agreement however, with previous observations by Neoh, et al. [19] and [30].

The observed decrease of the modal primary diameter has already been observed by TEM analysis $[23,26]$ but, to our knowledge, a quantitative description of the geometric standard deviation has never been performed before. Both the modal diameter decreases and the geometric standard deviation increases as a function of the HAB, reported in Fig. 8, can successfully be modeled. Indeed, by considering the distribution of the injected soot as a starting point, we can show that the log-normal distribution of the primary spheres, measured at any $\mathrm{HAB}$, can be modeled with the equation given in Eq. (14).

$$
\begin{gathered}
\frac{d \widetilde{D_{p}}}{d t}=-\frac{1}{\tau}{\widetilde{D_{p}}}^{n} \Leftrightarrow \frac{d \widetilde{V_{p}}}{d t}=-\frac{3}{\tau}{\widetilde{D_{p}}}^{n+2} \\
\text { with } \widetilde{D_{p}}=\frac{D_{p}}{D_{p, g e o}(H A B=0)} \text { and } \widetilde{V_{p}}=\frac{V_{p}}{V_{p, g e o}(H A B=0)}
\end{gathered}
$$

In Eq. (14), $\tau$ is a characteristic time of the mass reduction process and $\mathrm{n}$ is a dimensionless parameter that reveals if the mass loss is proportional to the primary sphere surface $(n=0)$ or volume $(n=1)$ or in between. The application of this modelling is illustrated in the left part of Fig. 9 for two HABs (14 mm and $26 \mathrm{~mm}$ respectively). It is clearly observed that the log-normal shape is well conserved by applying this model. The central column of Fig. 9 presents the parameters $n$ and $\tau$ adapted to best fit the model (Eq. (14)) on the SAXS data interpretation (Fig. 8) for each HAB. The power exponent $n$ is shown to decrease with HAB but it seems to remain between 0 and 1. According to Eq. (14) expressed 
in terms of primary sphere volume, it appears that the primary sphere volume or mass rate reduction is proportional to $D_{p}$ to the power of $n+2$ with $2<n+2<3$. This suggests that the oxidation process is not limited to a pure surface reaction but seems to be reactive with a shell of the primary spheres in accordance with observations by [9] "the disintegration of soot particles occurring in the late stage of oxidation is not due to the dissociation of carbon atoms at the edges of layer planes but is due rather to the stripping of small crystallites existing on the outer surface of the soot particles”. The greater the residence time, the more $n$ decreases indicating that the thickness of the reacting shell decreases, i.e. the oxidation regime is transient from regime 2 to regime 3 based on the definition reported by Stanmore, et al. [4]. That corresponds to a transition from a volume to surface reaction of the oxidative species.

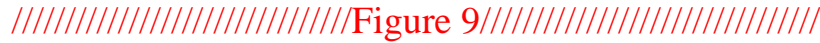

The right-hand column of Fig. 9 represents the flame temperature and the mole fractions of main oxidants determined by Chemkin (see supplementary material 2). That progressive transition from a bulk to a surface oxidation process can be explained by a progressive transition from an oxidation mostly caused by $\mathrm{O}_{2}$ at smaller heights in the flame even at lower temperatures to $\mathrm{OH}$ at higher positions $[20,28]$ and higher temperatures, consistently with $\mathrm{OH}$ and $\mathrm{O}_{2}$ variations in flat flame burners [76, 77]. Because of the increasing temperatures and oxidation that both participate at the particle level of graphitization, it is also possible that an increase of soot maturity limits the oxidation by $\mathrm{O}_{2}$ to a surface process as observed by Sediako, et al. [23]. $n \neq 1$ is directly responsible for the change of the geometrical standard deviation. On the other hand, the parameter $\tau$ is an indicator of the rate at which the primary particle diameter decreases during the oxidation process. It is shown in Fig. 9, that the characteristic time $\tau$ also decreases with HAB. This can be consistent with the fact that the decreases in the accessible oxidizing material (thickness of the shell related to $n$ ) may be reduced with HAB. 
Figure 10-A shows in red, the mass concentration $C_{s}=\rho_{p} f_{V}$ deduced from the corrected LII measurement and by considering the bulk density reported in Table 1 as a function of the residence time. For this calculation, the bulk density $\rho_{p}$ is considered to be constant suggesting that the desorption of volatile organic components and internal graphitization due to the high temperatures, is reduced as reported by Kandas, et al. [78]. This is a reasonable assumption for the present combustion conditions of the miniCAST since as soon as injected into the flame, the particles considered present a very low content of organic materials (Table 1) and a relatively ordered microstructure [50].

Consequently, providing a constant coefficient mass based reaction rate $k_{m}$, the observed exponential decrease of the mass concentration in Fig. 10-A could be interpreted as a natural solution of the pseudo-first-order rate equation (Eq. (15)), often considered for the evaluation of the mass reduction during the oxidation process.

$$
\frac{d C_{s}}{d t}=-k_{m} C_{s}
$$

Nevertheless, the thermally induced dilution occurring in the flame may also be responsible for a decrease of the determined mass concentration, without invoking any oxidation. Fortunately, this thermally induced dilution can be determined from the flame velocity measurements reported in Fig. 2-B (see supplementary material 3 for explanation of the method). On the other hand, a radial dilution of the particles caused by turbulent mixing or by Brownian motion could also participate to a decrease of the local particle mass fraction. The present flame is laminar and, over the considered HAB, the turbulent mixing layer thickness is negligible. Concerning the Brownian diffusion, a theoretical evaluation of the root mean square distance crossed by the particles $x_{r m s}=\sqrt{2 D t_{r e s}}$ is proposed. The corresponding distance is maximized by evaluating the largest diffusivity of the particles (evaluated to be $4 \times 10^{-9} \mathrm{~m}^{2} / \mathrm{s}$ ) along the central axis for $\mathrm{HAB}<30 \mathrm{~mm}$. It results in a maximum radial displacement of about $16 \mu \mathrm{m}$, negligible compared to the diameter of the central hole $(6 \mathrm{~mm})$. Note furthermore that thermophoresis effects are considered to limit radial diffusion. Consequently, the proposed $\mathrm{k}_{\mathrm{m}}$ coefficient is considered to be indicative of the oxidation process. It is shown to strongly 
decrease with residence time (continuous blue curve in Fig. 10-A). The observed decrease suggests that oxidation efficiency decreases with HAB even if the local temperature increases. This result is in agreement with the previously commented decrease of parameters $n$ and $\tau$ in Fig. 9 .

Figure 10-B also presents the ratio between the aggregate surface and the mass (in blue solid circles). The thus determined soot surface area once injected into the flame is found to be $120 \mathrm{~m}^{2} / \mathrm{g}$ in very good agreement with the value of $137 \mathrm{~m}^{2} / \mathrm{g}$ reported by Monge, et al. [79] for the same operating condition of the miniCAST. The observed increase is directly caused by the primary particle size reduction. That increase and the corresponding order of magnitude, are in good agreement with results reported by Ishiguro, et al. [9] and Kandas, et al. [78], for diesel soot, even if those measurements were made at lower temperatures. These authors invoked a change of the internal porosity during the oxidation process. In the present case, the observed increase of the surface/mass ratio is derived from a determination of the primary particle size reduction by means of the SAXS technique, with the hypothesis of smooth surface spheres (Porod exponent remaining equal to 4).

Based on the assumption that oxidation is a surface based mechanism, [29], Neoh, et al. [80], and also Echavarria, et al. [20] among others preferred, in respect to the first order law (Eq. (15)), to introduce another parameter called specific soot burnout rate $W$ :

$$
\frac{d C_{s}}{d t}=-W A
$$

with $A$, representing the soot available surface area $\left(\mathrm{m}^{2} / \mathrm{m}^{3}\right)$. In fact, it can be shown that $W$ is simply obtained by dividing $k_{m}$ (reported in Fig. 10-A) by the specific surface (surface - mass ratio fit reported in Fig. 10-B). The specific soot burnout rate thus determined is shown in red in Fig. 10-B. The order of magnitude of this parameter falls well into the range covered by flame measurements reviewed in [14]. The results obtained appear to be 10 to 100 times smaller than values reported by Garo, et al. [29] (optical measurements) and Ghiassi, et al. [28] (SMPS measurements) corresponding to larger temperatures and by considering spherical particles in their measurements analysis. On the other hand, the results reported in this study are in agreement with those determined by Lee, et al. [25] and Echavarria, et al. [20]. In the present study, this parameter is found to decrease with HAB, 
consistent with the decrease of the reactive shell thickness on the primary sphere surface as described above.

\section{CONCLUSION}

In-situ analysis of an in-flame soot oxidation process has been performed by coupling three optical techniques namely SAXS (x-ray scattering), SLS (visible light scattering) and LII (laser induced incandescence). The complementarity of these techniques allowed the soot volume fraction, the aggregate size, the aggregate density and the primary sphere size distribution to be determined. Nevertheless, many cautions are needed to satisfactorily couple these techniques, such as taking into account the local temperature change along the flame for the interpretation of the LII as well as of multiple scattering for the SLS results. In order only to observe the oxidation process, soot produced by a miniCAST generator and characterized by non-optical techniques (TEM/PPS/TEOM/SMPS) were injected into a non-sooting flame.

A strong agglomeration process was detected at lower heights above the burner certainly due to the increase of the particle mobility caused by the reduction in mass of the particles and the increase of the local temperature. This phenomenon was followed by the breakup of the soot aggregates when the sizes of the primary particles are reduced by a factor of $20 \%$ corresponding to the initial degree of primary spheres overlap, suggesting breakup occurring at the connection between primary spheres. This study also allowed the evolution of the primary particle size distribution to be determined. It was shown that the decrease of the modal diameter was accompanied by a significant increase in the geometric standard deviation. A model has been proposed to mimic this behavior suggesting that the oxidation process acts on a shell surrounding the primary sphere, whose thickness decreases during the oxidation process resulting in a decrease of the oxidation efficiency. This decrease of oxidation efficiency is confirmed by the observed decrease of the first order reaction mass rate and of the specific soot burnout rate that are shown to decrease with the height above the burner. Finally, it was shown that the surface area increases during oxidation due to the monomer diameter decrease without invoking any change of the soot microstructure. 
One perspective of this work is to apply the same coupling of techniques with injection into nonsooting flames of different temperatures and of soot presenting other initial compositions and microstructures. The effect of additives (ferrocene, halogens, urea, etc.) on the oxidation of soot particles is another main perspective of the present study. A precise determination of the residence time at lower HAB in the flame (by PIV for example) and an experimental determination of the surrounding oxidizing species concentrations would be helpful for the exploitation of these results for kinetic models.

\section{FUNDING AND ACKNOWLEDGMENTS}

This work was conducted within the framework of French Carnot Institute Energy and Propulsion Systems (ESP, project Dimosoot). We acknowledge the staff and facilities of SOLEIL for the provision of synchrotron radiation facilities.

\section{REFERENCES}

[1] H. WANG, "FoRMATION OF NASCENT SOOT AND OTHER CONDENSED-PHASE MATERIALS IN FLAMES," P. COMBUST. INST., VOL. 33, PP. 41-67, 2011.

[2] P. Desgroux, X. Mercier, and K. A. Thomson, "Study of the formation of SOOT AND ITS PRECURSORS IN FLAMES USING OPTICAL DIAGNOSTICS," $P$. COMBUST. INST., VOL. 34, PP. 1713-1738, 2013.

[3] H. A. Michelsen, "PRobing soot formation, ChEMicAl AND PHYSiCAL EVOLUTION, AND OXIDATION: A REVIEW OF IN SITU DIAGNOSTIC TECHNIQUES AND NEEDS," P. COMBUSt. INST., VOL. 36, PP. 717-735, 2017/01/01/ 2017.

[4] B. R. Stanmore, J. F. Brilhac, and P. Gilot, "The oxidation of SOOT: A REVIEW OF EXPERIMENTS, MECHANISMS AND MODELS," CARBON, VOL. 39, PP. 2247-2268, 2001.

[5] S. Mahamulkar, K. Yin, P. K. Agrawal, R. J. Davis, C. W. Jones, A. Malek, AND H. SHIBATA, "FORMATION AND OXIDATION/GASIFICATION OF CARBONACEOUS DEPOSITS: A REVIEW," INDUSTRIAL \& ENGINEERING CHEMISTRY RESEARCH, VOL. 55, PP. 9760-9818, 2016.

[6] J. S. BHATT AND R. P. LINDSTEDT, "ANALYSIS OF THE IMPACT OF AGGLOMERATION AND SURFACE CHEMISTRY MODELS ON SOOT FORMATION AND OXIDATION," PROC. COMBUST. INST., VOL. 32, PP. 713-720, 2009/01/01/ 2009.

[7] M. Sirignano, H. Ghiassi, A. D'ANNA, AND J. S. Lighty, "TEMPERATURE AND OXYGEN EFFECTS ON OXIDATION-INDUCED FRAGMENTATION OF SOOT PARTICLES," COMBUST. AND FLAME, VOL. 171, PP. 15-26, 2016/09/01/ 2016. 
[8] K. J. Higgins, H. Jung, D. B. Kittelson, J. T. Roberts, And M. R. Zachariah, "SIZE-Selected NANOPARTICle Chemistry: Kinetics of SoOt OxidATIOn," J. Phys. Chem. A, vol. 106, Pp. 96-103, 2002/01/01 2002.

[9] T. ISHIGURO, N. SUZUKI, Y. FUJITANI, AND H. MORIMOto, "MicrostruCtURAL CHANGES OF DIESEL SOOT DURING OXIDATION," COMBUST. FLAME, VOL. 85, PP. 1-6, 1991.

[10] H. Jung, D. B. KitTelson, and M. R. Zachariah, "Kinetics and Visualization OF SOOT OXIDATION USING TRANSMISSION ELECTRON MICROSCOPY," COMBUST. FLAME, VOL. 136, PP. 445-456, 2004.

[11] S. KIM, R. FletcheR, AND M. ZACHARIAH, "UNDERSTANDING THE DIFFERENCE IN OXIDATIVE PROPERTIES BETWEEN FLAME AND DIESEL SOOT NANOPARTICLES: THE ROLE OF METALS," ENV. SC. AND TECH., VOL. 39, PP. 4021-4026, 2005.

[12] X. MA, C. ZANGmeister, AND M. ZAChaRIAH, "SOOT OXIDATION KINETICS: A COMPARISON STUDY OF TWO TANDEM ION-MOBILITY METHODS," J. PHYS. CHEM. C, VOL. 117, PP. 10723-10729, 2013.

[13] S. I. Seher, M. N. Ess, H. Bladt, R. Niessner, G. Eigenberger, AND U. NIEKEN, "A COMPARISON OF DIESEL SOOT OXIDATION RATES MEASURED WITH TWO DIFFERENT ISOTHERMAL SET-UPS," J. AEROSOL SCI., VOL. 91, PP. 94-100, 2016/01/01/2016.

[14] H. Guo, P. M. Anderson, and P. B. Sunderland, "Optimized Rate EXPRESSIONS FOR SOOT OXIDATION BY OH AND O2," FUEL, VOL. 172, PP. 248252, 2016/05/15/ 2016.

[15] Y. Gallo, V. B. Malmborg, J. Simonsson, E. Svensson, M. Shen, P.-E. BengtSSON, J. PAgels, M. TunÉr, A. GARCia, AND Ö. ANDERSSON, "INVESTIGATION OF LATE-CYCLE SOOT OXIDATION USING LASER EXTINCTION AND IN-CYLINDER GAS SAMPLING AT VARYING INLET OXYGEN CONCENTRATIONS IN DIESEL ENGINES," FUEL, VOL. 193, PP. 308-314, 2017.

[16] M. E. Mueller, G. Blanquart, and H. Pitsch, "Modeling the oxidationINDUCED FRAGMENTATION OF SOOT AGGREGATES IN LAMINAR FLAMES," $P$. COMBUST. INST., VOL. 33, PP. 667-674, 2011.

[17] A. Khosousi AND S. B. DWORKIN, "DetaILED MOdelling of SOOT OXIDATION BY O2 AND OH IN LAMINAR DIFFUSION FLAMES," P. COMBUST. INST., VOL. 35, PP. 1903-1910, 2015/01/01/ 2015.

[18] F. Xu, A. El-Leathy, C. Kim, and G. Faeth, "Soot surface oxidation in HYDROCARBON/AIR DIFFUSION FLAMES AT ATMOSPHERIC PRESSURE," COMBUST. FLAME, VOL. 132, PP. 43-57, 2003.

[19] K. G. NeOH, J. B. Howard, and A. F. SARofim, "EfFect of oxidation on the PHYSICAL STRUCTURE OF SOOT," P. COMBUST. INST., VOL. 20, PP. 951-957, 1985/01/01 1984 .

[20] C. A. Echavarria, I. C. JaRamillo, A. F. Sarofim, and J. S. Lighty, "Studies OF SOOT OXIDATION AND FRAGMENTATION IN A TWO-STAGE BURNER UNDER FUEL- 
LEAN AND FUEL-RICH CONDITIONS," P. COMBUST. INST., VOL. 33, PP. 659-666, 2011.

[21] H. GHIASSi, P. TOth, I. C. JARAMILLO, AND J. S. Lighty, "SOOT OXIDATIONINDUCED FRAGMENTATION: PART 1: THE RELATIONSHIP BETWEEN SOOT NANOSTRUCTURE AND OXIDATION-INDUCED FRAGMENTATION," COMBUST. FLAME, VOL. 163, PP. 179-187, 2016/01/01/ 2016.

[22] H. Ghiassi, I. C. JaRAmillo, P. TOth, AND J. S. Lighty, "SOOT OXIDATIONINDUCED FRAGMENTATION: PART 2: EXPERIMENTAL INVESTIGATION OF THE MECHANISM OF FRAGMENTATION," COMBUST. FLAME, VOL. 163, PP. 170-178, 2016/01/01/ 2016.

[23] A. D. Sediako, C. SoOng, J. Y. Howe, M. R. Kholghy, and M. J. Thomson, "REAL-TIME OBSERVATION OF SOOT AGGREGATE OXIDATION IN AN EnVIRONMENTAL TRANSMission ElECtRon Microscope," P. COMBUSt. INST., VOL. 36, PP. 841-851, 2017/01/01/ 2017.

[24] A. KHOSOUSI AND S. B. DWORKIN, "SOOT SURFACE REACTIVITY DURING SURFACE GROWTH AND OXIDATION IN LAMINAR DIFFUSION FLAMES," COMBUST. FLAME, VOL. 162, PP. 4523-4532, 2015/12/01/ 2015.

[25] K. B. Lee, M. W. Thring, and J. M. BeÉr, "On the Rate of combustion of SOOT IN A LAMINAR SOOT Flame," COMBUSt. Flame, VOL. 6, PP. 137-145, 1962/01/01 1962.

[26] R. Puri, R. J. SANTORO, ANd K. C. SMYth, "The oxidATION OF SOOT AND CARBON MONOXIDE IN HYDROCARBON DIFFUSION FLAMES," COMBUST. FLAME, VOL. 97, PP. 125-144, 1994.

[27] M. M. Constantine And A. D. Richard, "COMParison of SoOt GRowTH AND OXIDATION IN SMOKING AND NON-SMOKING ETHYLENE DifFUSION FLAMES," COMBUST. SCI. AND TECH., VOL. 66, PP. 1-16, 1989/07/01 1989.

[28] H. GhiAssi, I. C. JARAMILLO, AND J. S. Lighty, "KINETICS OF SOOT OxidATION By MoleCUlar OXYGEN IN A PREMIXEd Flame," ENERGY \& FUelS, VOL. 30, PP. 3463-3472, 2016/04/21 2016.

[29] A. Garo, G. Prado, and J. Lahaye, "Chemical aspects of Soot particles OXIDATION IN A LAMINAR METHANE-AIR DIFFUSION FLAME," COMBUST. FLAME, VOL. 79, PP. 226-233, 1990/03/01 1990.

[30] A. Garo, J. LaHAYE, and G. Prado, "Mechanisms of Formation and DESTRUCTION OF SOOT PARTICLES IN A LAMINAR METHANE-AIR DIFFUSION FLAME," SYMP. ON COMBUST., VOL. 21, PP. 1023-1031, 1988/01/01 1988.

[31] R. Puri, T. Richardson, R. Santoro, and R. Dobbins, "Aerosol dynamic PROCESSES OF SOOT AGGREGATES IN A LAMINAR ETHENE DIFFUSION FLAME," COMBUST. FLAME, VOL. 92, PP. 320-333, 1993.

[32] F. Xu, P. B. Sunderland, ANd G. M. FAeth, "SOOT FORMATION IN LAMinaR PREMIXED ETHYLENE/AIR FLAMES AT ATMOSPHERIC PRESSURE," COMBUST. FLAME, VOL. 108, PP. 471-493, 1997. 
[33] M. SiRignano, H. GhiAssi, A. D'ANNA, AND J. S. Lighty, "TEMPERATURE AND OXYGEN EFFECTS ON OXIDATION-INDUCED FRAGMENTATION OF SOOT PARTICLES," COMBUST. FLAME, VOL. 171, PP. 15-26, 2016.

[34] R. A. Dobbins AND C. M. Megaridis, "ABSORPtion AND SCATTERING OF LIGHT BY POLYDISPERSE AGgREGATES," APPL. OPT., VOL. 30, PP. 4747-4754, 1991.

[35] F. Ossler, L. Vallenhag, S. E. Canton, J. B. A. Mitchell, J.-L. Le Garrec, M. SZTUCKI, AND S. DI STASIO, "DYNAMICS OF INCIPIENT CARBON PARTICLE FORMATION IN A STABILIZED ETHYLENE FLAME BY IN SITU EXTENDED-SMALLANGLE- AND WIDE-ANGLE X-RAY SCATTERING," CARBON, VOL. 51, PP. 1-19, 2013.

[36] S. Di Stasio, J.-L. LeGarRec, And J. Mitchell, "SYNCHROtRon Radiation STUDIES OF ADDITIVES IN COMBUSTION, II: SOOT AGGLOMERATE MICROSTRUCTURE CHANGE BY ALKALI AND ALKALINE-EARTH METAL ADDITION TO A PARTIALLY PREMIXED FLAME," ENERGY \& FUELS, VOL. 25, PP. 916-925, 2011.

[37] S. Di StAsio, J. MitChell, J. LegarReC, L. BienNieR, AND M. WULFF, "SYNCHROTRON SAXS <IN SITU> IDENTIFICATION OF THREE DIFFERENT SIZE MODES FOR SOOT NANOPARTICLES IN A DIFFUSION FLAME," CARBON, VOL. 44, PP. 1267-1279, 2006.

[38] J. Mitchell, J. LegarReC, A. Florescumitchell, and S. Distasio, "SmallANGLE NEUTRON SCATTERING STUDY OF SOOT PARTICLES IN AN ETHYLENE-AIR DifFusion flame," COMBUSt. Flame, VOL. 145, PP. 80-87, 2006.

[39] J. Mitchell, J.-L. LeGarRec, G. Saidani, F. LefeuvRe, and S. Di Stasio, "SYNCHROTRON RADIATION STUDIES OF ADDITIVES IN COMBUSTION, III: FERROCENE," ENERGY \& FUELS, VOL. 27, PP. 4891-4898, 2013.

[40] J. Hessler, S. Seifert, and R. Winans, "Spatially REsolved SMALL-ANGle X-RAY SCATTERING STUDIES OF SOOT INCEPTION AND GROWTH," PROCEEDINGS OF THE COMBUSTION INSTITUTE, VOL. 29, PP. 2743-2748, 2002.

[41] H. Michelsen, C. Schulz, G. Smallwood, And S. Will, "LASER-INDUCed INCANDESCENCE: PARTICULATE DIAGNOSTICS FOR COMBUSTION, ATMOSPHERIC, AND INDUSTRIAL APPLICATIONS," PROG. ENERG. COMBUST., VOL. 51, PP. 2-48, 2015.

[42] H. J. Seong and A. L. Boehman, "Studies of soot oxidative Reactivity USING A DIFFUSION FLAME BURNER," COMBUST. FLAME, VOL. 159, PP. 18641875, 2012.

[43] T. IshiguRo, Y. YAKATORI, AND K. AKIHAMA, "Microstructure OF DIESEL SOOT PARTICLES PROBED BY ELECTRON MICROSCOPY: FIRST OBSERVATION OF INNER CORE AND OUTER SHELL," COMBUST. FLAME, VOL. 108, P. 231, 1997.

[44] J. Schmid, B. GRoB, R. Niessner, and N. P. IVLeVA, "MultiwaVelength RAMAN MICROSPECTROSCOPY FOR RAPID PREDICTION OF SOOT OXIDATION REACTIVITY," ANAL. CHEM., VOL. 83, PP. 1173-1179, 2011. 
[45] L. Yang, Z. Wang, Y. Zhu, Z. Li, J. Zhou, Z. Huang, and K. Cen, "Premixed JET FLAME CHARACTERISTICS OF SYNGAS USING OH PLANAR LASER INDUCED FLUORESCENCE," CHINESE SCIENCE BULLETIN, VOL. 56, PP. 2862-2868, 2011.

[46] R. L. VANDER WAL AND L. J. HALL, "FERRocene AS A PRECuRsor REAGent For METAL-CATALYZED CARBON NANOTUBES: COMPETING EFFECTS," COMBUSTION AND FLAME, VOL. 130, PP. 27-36, 2002/07/01/ 2002.

[47] R. Lemaire, E. Therssen, and P. Desgroux, "Effect of ethanol addition IN GASOLINE AND GASOLINE-SURROGATE ON SOOT FORMATION IN TURBULENT SPRAY FLAMES," FUEL, VOL. 89, PP. 3952-3959, 2010.

[48] R. H. Moore, L. D. Ziemba, D. Dutcher, A. J. Beyersdorf, K. Chan, S. Crumeyrolle, T. M. RAYMOnd, K. L. ThORNhill, E. L. Winstead, and B. E. ANDERSON, "MAPPING THE OPERATION OF THE MiniATURE COMBUStION Aerosol Standard (Mini-CASt) Soot Generator," Aerosol SCl. TeCh., VOL. 48, PP. 467-479, 2014.

[49] J. Yon, A. Bescond, ANd F. X. OUF, "A Simple SEMI-EMPIRICAL MODEL FOR EFFECTIVE DENSITY MEASUREMENTS OF FRACTAL AGGREGATES," J. AEROSOL SCl., VOL. 87, PP. 28-37, 2015.

[50] A. Bescond, J. Yon, F. X. Ouf, C. Rozé, A. Coppalle, P. Parent, D. Ferry, AND C. LAFFON, "SOOT OPTICAL PROPERTIES DETERMINED BY ANALYZING EXTINCTION SPECTRA IN THE VISIBLE NEAR-UV: TOWARD AN OPTICAL SPECIATION ACCORDING to CONSTITUENTS AND StRUCtuRE," J. AEROSOl SCl., VOl. 101, PP. 118-132, 2016.

[51] D. Bradley and K. Matthews, "Measurement of high gas temperatures WITH FINE WIRE THERMOCOUPLES," J. MECH. ENG. SCI., VOL. 10, PP. 299-305, 1968.

[52] V. J. LyONS AND C. M. GRACiA-SALCEdo, "DEtermination of COMBustion GAS TEMPERATURES BY INFRARED RADIOMETRY IN SOOTING AND NONSOOTING FLAMES," DTIC DOCUMENT, HTTP://WWW.DTIC.MIL/DOCS/CITATIONS/ADA2053731989.

[53] J. SeitZMAN, R. WAinNeR, ANd P. YANG, "SOOT-VELOCITY MEASUREMENTS BY PARTICLE VAPORIZATION VELOCIMETRY," OPT. LETT., VOL. 24, PP. 1632-1634, 1999.

[54] W. KONG AND F. LIU, "NUMERICAL STUdY OF THE EFFECTS OF GRAVITY ON SOOT FORMATION IN LAMINAR COFLOW METHANE/AIR DIFFUSION FLAMES UNDER DiffERENT AIR STREAM VElocities," COMBUSt. THEOR. MODEL., VOL. 13, PP. 993-1023, 2009.

[55] G. D. Förster, M. Girault, J. Menneveux, L. Lavisse, J.-M. Jouvard, M. D. C. M. DE LUCAS, V. Potin, F.-X. OUF, M. KeRKAR, AND J.-L. Le GARREC, "OXIDATION-INDUCED SURFACE ROUghENING OF AluminUm NANOPARTICLES Formed in an Ablation Plume," Phys. ReV. LetT., vol. 115, P. 246101, 2015. 
[56] C. M. SORENSEN, "Q-SPACE ANALYSIS OF SCATTERING BY PARTICLES: A REVIEW," J. QuANT. SPECTROSC. RADIAT. TRANSFER, VOL. 131, PP. 3-12, 2013.

[57] U. KöylÜ and G. FAeth, "Radiative PROperties of Flame-generated SOOt," J. HEAT TRANS. -T ASME VOL. 115, 1993.

[58] Ü. Ö. KÖYLÜ AND G. M. FAETH, "OPTICAL PROPERTIES OF OVERFIRE SOOT IN BUOYANT TURBULENT DIFFUSION FLAMES AT LONG RESIDENCE TIMES," J. HEAT TRANSF., VOL. 116, PP. 152-159, 1994.

[59] S. De IUlis, S. Maffi, F. Cignoli, and G. ZizaK, "Three-Angle SCATTERING/EXTINCTION VERSUS TEM MEASUREMENTS ON SOOT IN PREMIXED ethylene/Air flame," APPl. Phys. B-LAsers O, vol. 102, PP. 891-903, 2010.

[60] C. Caumont-Prim, J. Yon, A. Coppalle, F.-X. Ouf, and K. Fang Ren, "MEASUREMENT OF AGGREGATES' SIZE DISTRIBUTION BY ANGULAR LIGHT SCATTERING," J. QUANT. SPECTROSC. RADIAT. TRANSFER, VOL. 126, PP. 140149, 2013.

[61] C. SORENSEN, "LIGHT SCATtering BY FRACTAL AGgREgATES: A REVIEW," AEROSOL SCI. TECH., VOL. 35, PP. 648-687, 2001

[62] J. Yon, F. Liu, A. Bescond, C. Caumont-Prim, C. Rozé, F. X. Ouf, and A. COPPALLE, "EFFECTS OF MULTIPLE SCATTERING ON RADIATIVE PROPERTIES OF SOOT FRACTAL AGgREgATES," J. QuANT. SPECTROSC. RADIAT. TRANSFER, VOL. 133, PP. 374-381, 2014.

[63] G. BEAUCAgE, "APPROXIMATIONS LEADING TO A UNIFIED EXPONENTIAL/POWERLAW APPROACH TO SMALL-ANGLE SCATTERING," J. OF APPL. CRYST., VOL. 28, PP. 717-728, 1995.

[64] G. Beaucage, H. Kammler, and S. Pratsinis, "Particle size distributions FROM SMALL-ANGLE SCATTERING USING GLOBAL SCATTERING FUNCTIONS," J.OF APPL. CRYST., VOL. 37, PP. 523-535, 2004.

[65] M. Sztucki, T. Narayanan, ANd G. Beaucage, "In Situ study of AGGREGATION OF SOOT PARTICLES IN AN ACETYLENE FLAME BY SMALL-ANGLE XRAy SCATtering," J. OF APPL. PHY., VOL. 101, PP. 114304-114304-7, 2007.

[66] H. Michelsen, F. LiU, B. F. Kock, H. Bladh, A. BoÏARciuc, M. Charwath, T. DREIER, R. HAdEF, M. HOFMANN, AND J. ReIMANN, "Modeling LASER-INDUCED INCANDESCENCE OF SOOT: A SUMMARY AND COMPARISON OF LII MODELS," APPL. PHYS. B-LASERS O, VOL. 87, PP. 503-521, 2007.

[67] J. ILAVSKY, "IRENA 2 PACKAGE OF SAS DATA EVALUATION AND MODELING MACROS FOR IGOR PRO," IN HTTP://USAXS.XRAY.APS.ANL.GOV/STAFF/ILAVSKY/IRENA.HTML, 2006.

[68] M. J. McDonald, "SMALL-ANGLE X-RAY SCATtERING STUDIES OF NANOSTRUCTURED RESPIRATOR AND BATTERY MATERIALS," HTTPS://DALSPACE.LIBRARY.DAL.CA/HANDLE/10222/386202014 2013. 
[69] T. T. ChARALAMPOPOULOS, "AN AUTOMATED LIGHT SCATTERING SYSTEM AND A METHOD FOR THE INSITU MEASUREMENT OF THE INDEX OF REFRACTION OF SOOT PARTICLES," REV. SCI. INSTRUM., VOL. 58, PP. 1638-1646, 1987.

[70] H. K. Kammler, G. Beaucage, D. J. Kohls, N. Agashe, and J. Ilavsky, "MONITORING SIMULTANEOUSLY THE GROWTH OF NANOPARTICLES AND AGGREGATES BY IN SITU ULTRA-SMALL-ANGLE X-RAY SCATTERING," JOURNAL OF APPLIED PHYSICS, VOL. 97, P. 054309, 2005.

[71] A. Bescond, J. Yon, F.-X. Ouf, D. Ferry, D. Delhaye, D. Gaffié, A. Coppalle, and C. Rozé, "Automated Determination of Aggregate PRIMARY PARTIClE SIZE DISTRIBUTION BY TEM IMAGE ANALYSIS: APPLICATION to SOOt," AEROSOl SCI. TECH., VOL. 48, PP. 831-841, 2014.

[72] A. M. Brasil, T. L. Farias, and M. G. Carvalho, "A Recipe for image CHARACTERIZATION OF FRACTAL-LIKE AgGREgAtES," J. AEROSOl SCI., VOL. 30, P. 1379, 1999.

[73] F.-X. Ouf, J. Yon, P. Ausset, A. Coppalle, And M. Maillé, "Influence of SAMPLING AND STORAGE PROTOCOL ON FRACTAL MORPHOLOGY OF SOOT Studied by TRANSmission EleCtron Microscopy," AEROSOl SCI. TECH., VOL. 44, PP. 1005 - 1017, 2010.

[74] D. Thomas, F. Ouf, F. Gensdarmes, S. Bourrous, and L. Bouilloux,

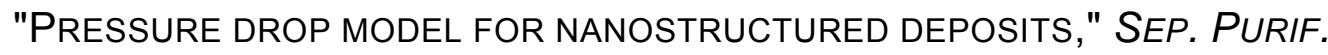
TECHNOL., VOL. 138, PP. 144-152, 2014.

[75] F. Pierce, C. Sorensen, and A. Chakrabarti, "Computer simulation of DIFFUSION-LIMITED CLUSTER-CLUSTER AGGREGATION WITH AN EPSTEIN DRAG FORCE," PHYS. REV. E, VOL. 74, 2006.

[76] T. A. Cool, K. Nakajima, C. A. TaAtjes, A. Mcllroy, P. R. Westmoreland, M. E. LAW, AND A. MOREL, "STUDIES OF A FUEL-RICH PROPANE FLAME WITH PHOTOIONIZATION MASS SPECTROMETRY," P. COMBUST. INST., VOL. 30, PP. 1681-1688, 2005/01/01/ 2005.

[77] P. R. Westmoreland, M. E. Law, T. A. CoOl, J. Wang, A. Mcllroy, C. A. TAATJES, AND N. HANSEN, "ANALYSIS OF FLAME STRUCTURE BY MOLECULARBEAM MASS SPECTROMETRY USING ELECTRON-IMPACT AND SYNCHROTRONPHOTON IONIZATION," COMBUST., EXPL. AND SHOCK WAVES, VOL. 42, PP. 672$677,2006 / 11 / 012006$.

[78] A. W. Kandas, I. G. Senel, Y. LeVendis, and A. F. Sarofim, "Soot surface AREA EVOLUTION DURING AIR OXIDATION AS EVALUATED BY SMALL ANGLE X-RAY SCATTERING AND CO 2 ADSORPTION," CARBON, VOL. 43, PP. 241-251, 2005.

[79] M. E. Monge, B. D’Anna, L. Mazri, A. Giroir-Fendler, M. Ammann, D. DonALDSON, AND C. GEORGE, "LIGHT CHANGES THE ATMOSPHERIC REACTIVITY OF SOOT," PROC. NAT. ACAD. SCI., VOL. 107, PP. 6605-6609, 2010.

[80] K. G. Neoh, J. B. Howard, and A. F. Sarofim, "Soot Oxidation in Flames," in Particulate Carbon: Formation DuRING Combustion, D. C. SiEgla AND G. W. SMITH, EdS., ED BOSTON, MA: SPRINGER US, 1981, PP. 261-282. 


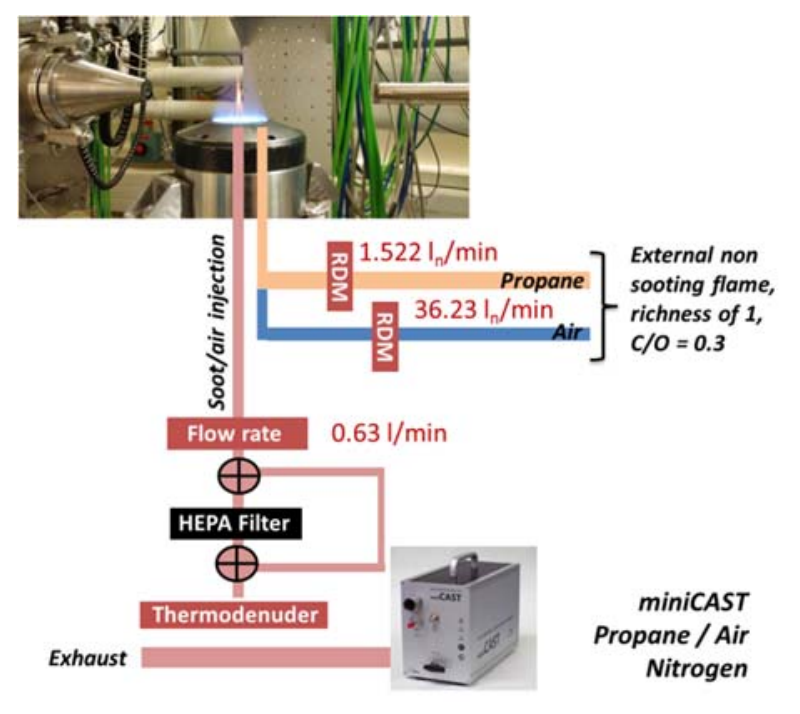

A: Injection of soot produced by miniCAST at the center of the non-sooting flame (modified McKenna Burner). The picture illustrates the SAXS experiment at the SOLEIL synchrotron (Swing beamline).

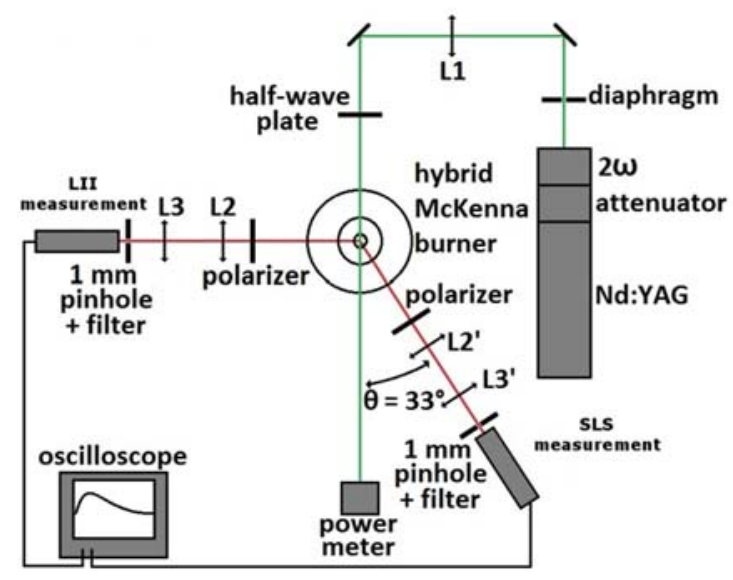

B: Experimental apparatus for the LII and SLS experiments (seen from above).

Fig. 1. Experimental setup 


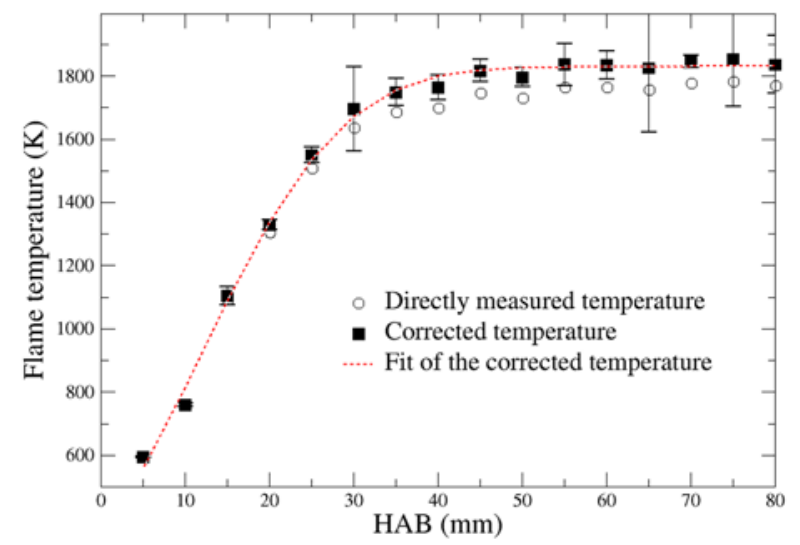

A: Temperature profile

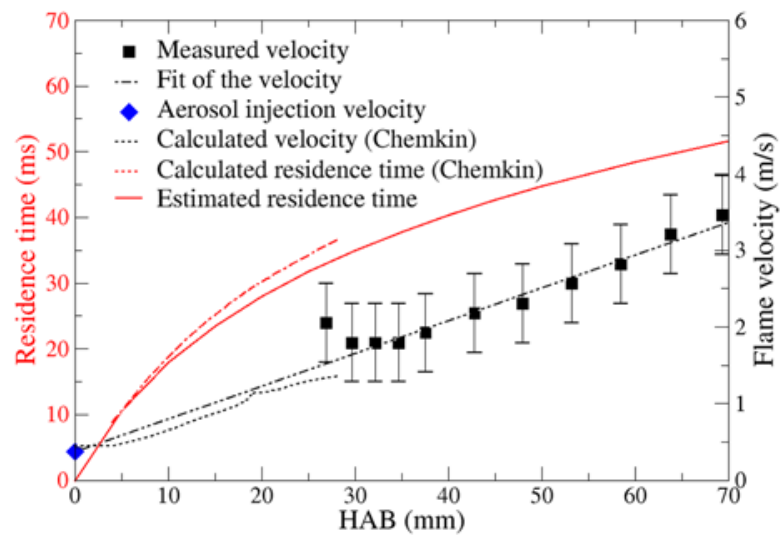

B: Residence time

Fig. 2. Determination of the non-sooting flame temperature and residence time as a function of the height above the burner (HAB). 


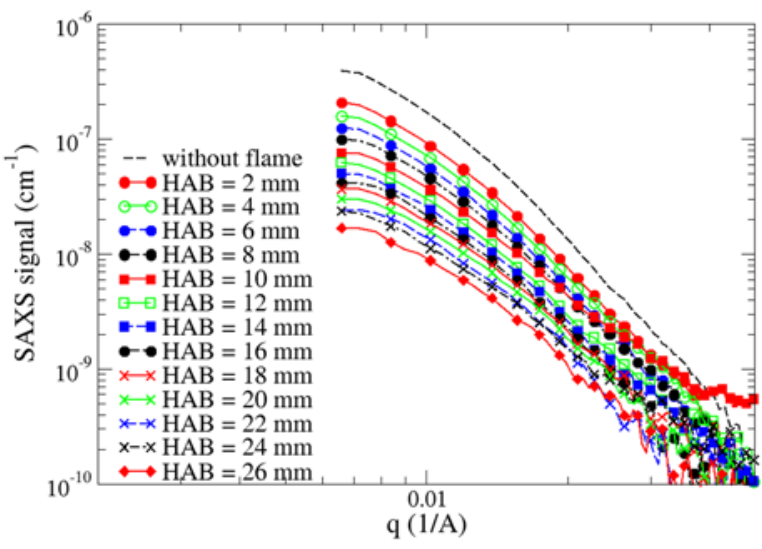

A: Conventional plot

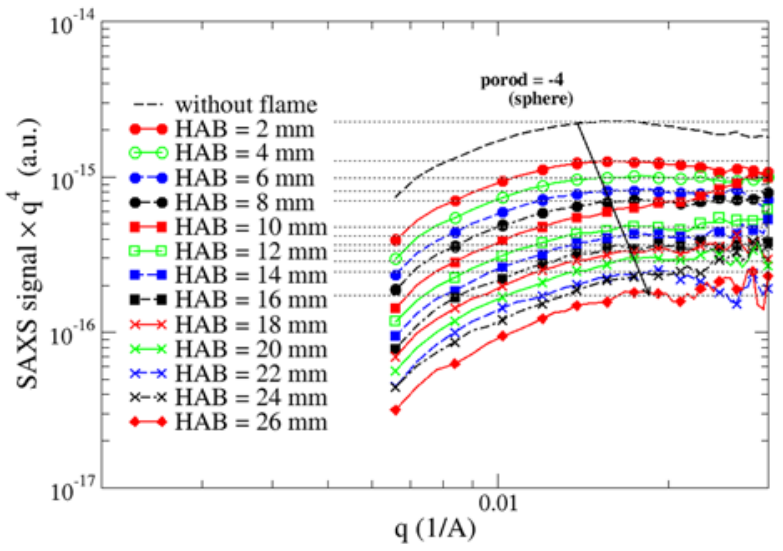

B: Porod plot

Fig. 3. Direct results of the SAXS signals as a function of the height above the burner (A) and same results presented as Porod plots (B). 

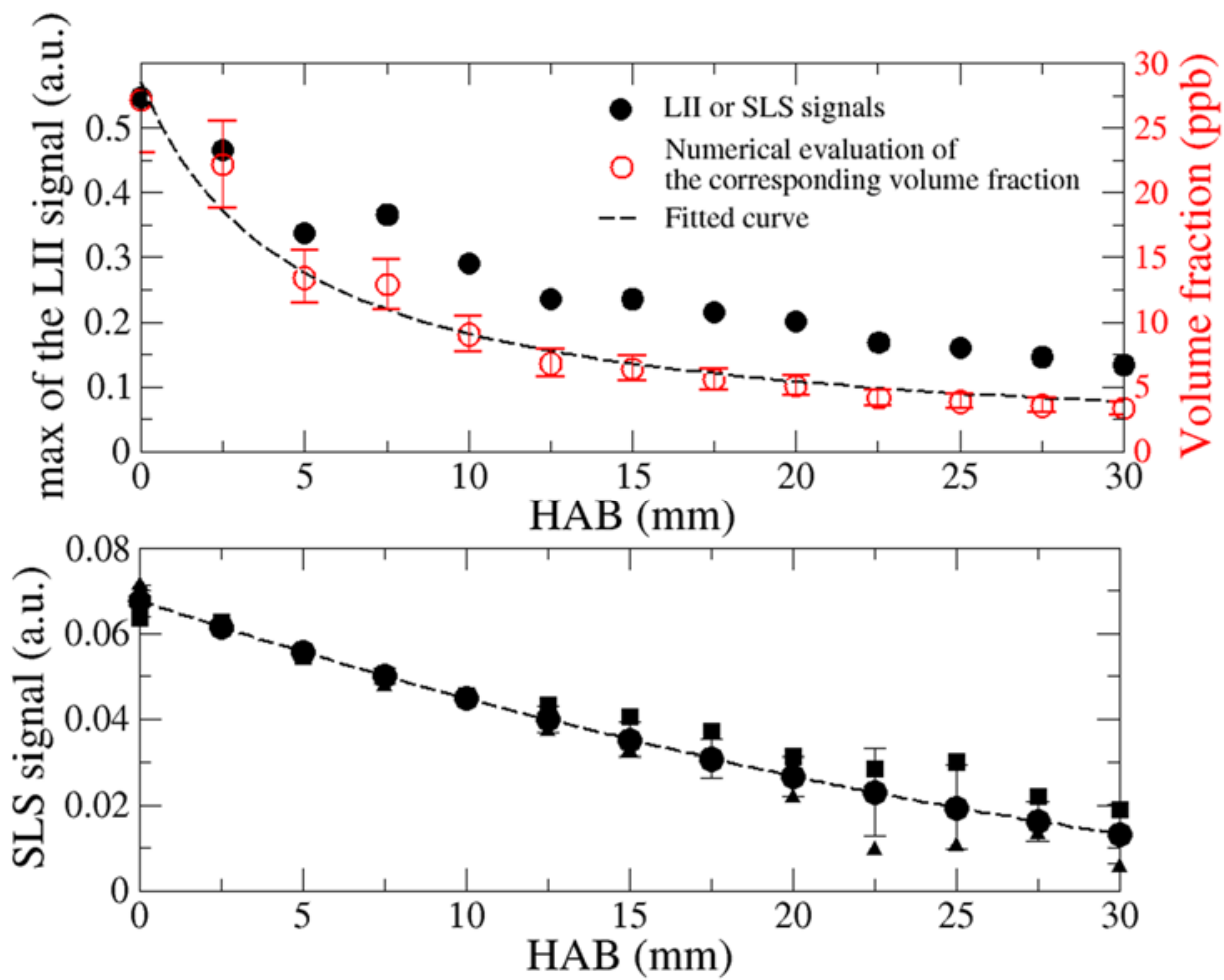

Fig. 4. Results of the Laser Induced Incandescence (upper panel) and Static Light Scattering measurements (lower panel). 


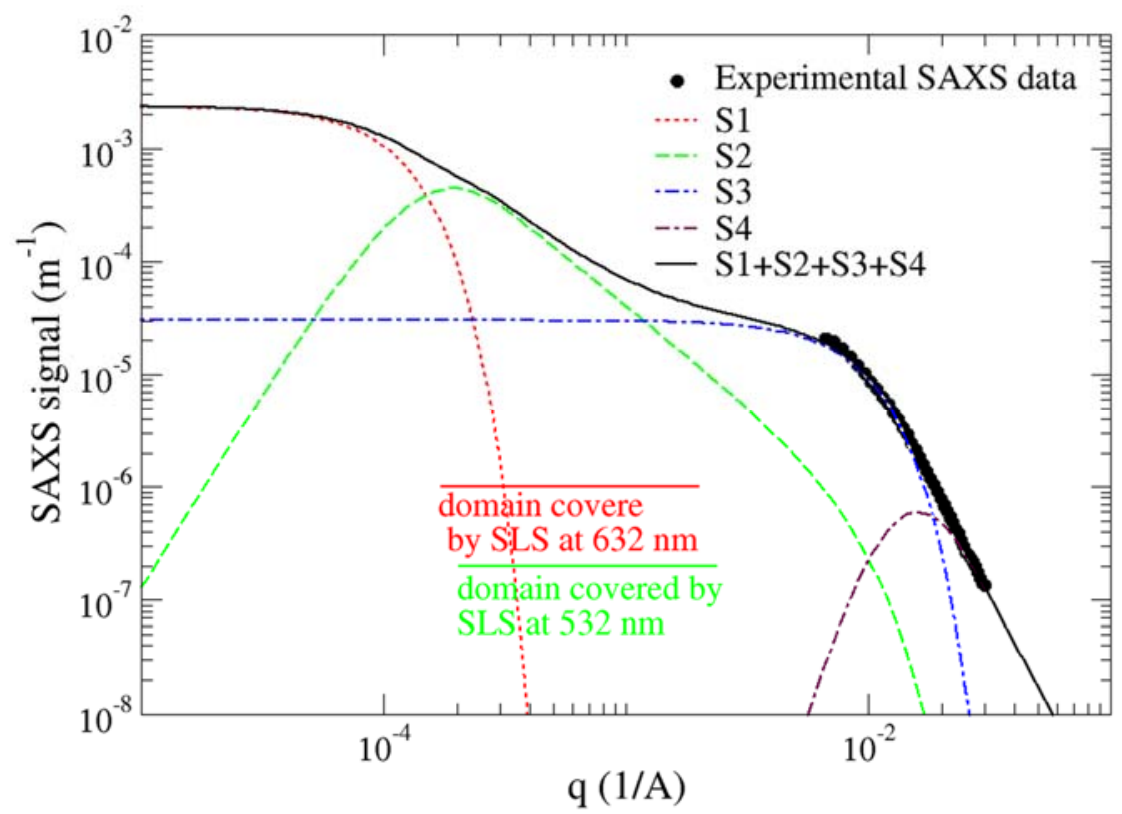

Fig. 5. Example of SAXS theoretical modeling corresponding to the experimental measurement at $\mathrm{HAB}=2 \mathrm{~mm}, \overline{N_{p}}=75, D_{p, g e o}=26.4 \mathrm{~nm}, \sigma_{p, g e o}=1.34, f_{V}=20 \mathrm{ppb}, \rho_{e}=3.59 \times$ $10^{27} \mathrm{~m}^{-3}, I_{e}=7.94 \times 10^{-30} \mathrm{~m}^{2}, P D I_{a}=2, D_{f}=1.73, p=4$. 


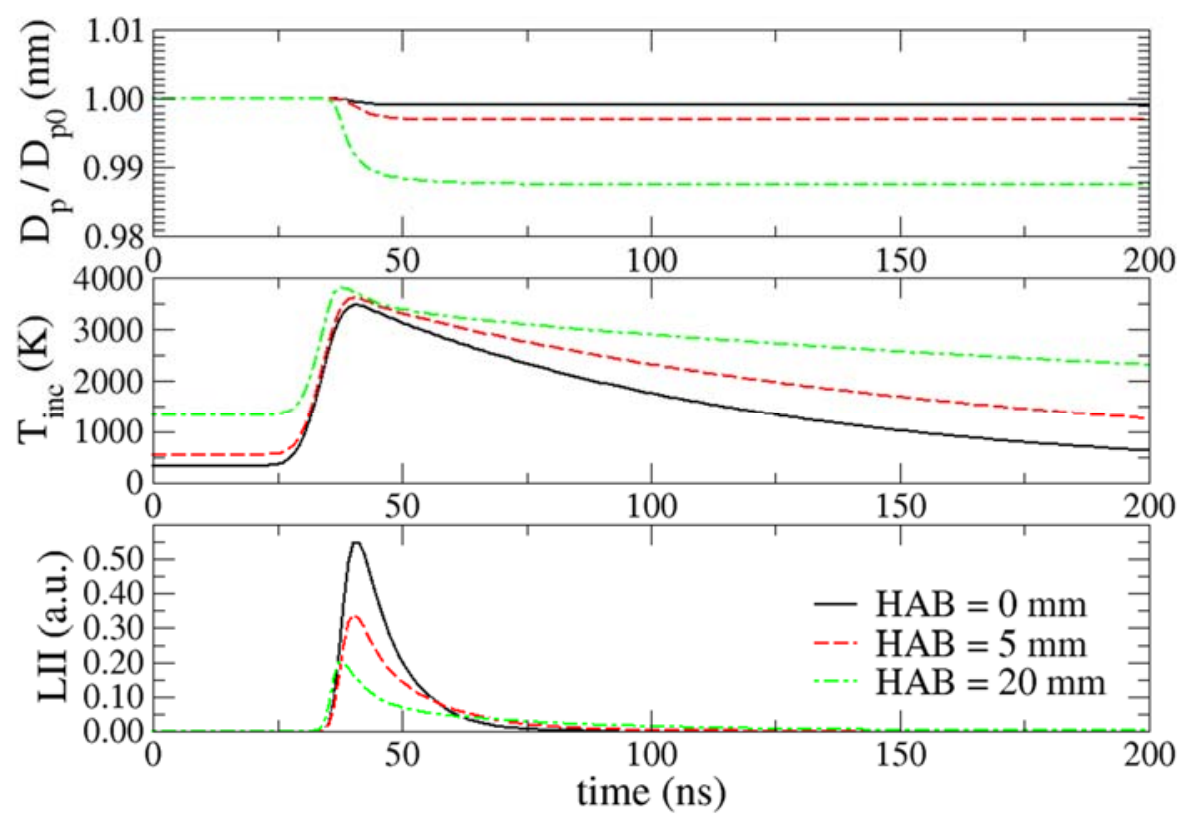

Fig. 6. Modeling of the temporal relative evolution of the primary sphere diameter, soot incandescence temperature and LII signal after laser pulse for soot injected in the flame at different heights above the burner. 


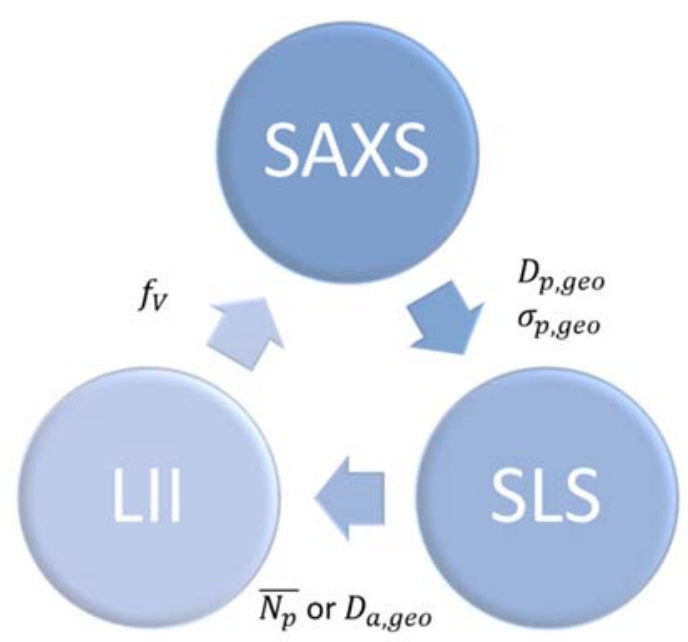

Fig. 7. Representation of the iteration procedure used for the determination of the parameters. 
$\times$ Pearson's correlation coefficient

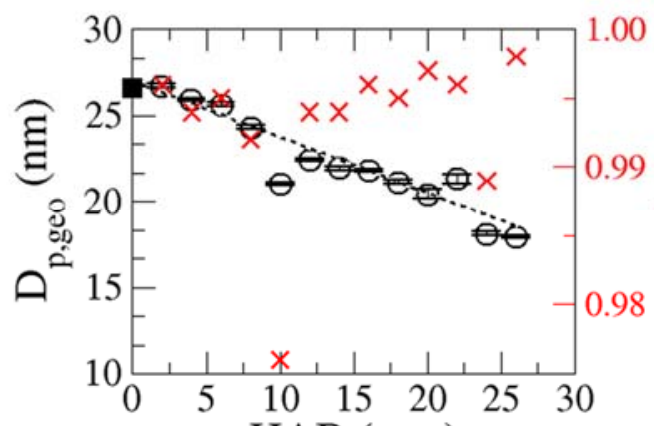

$\operatorname{HAB}(\mathrm{mm})$

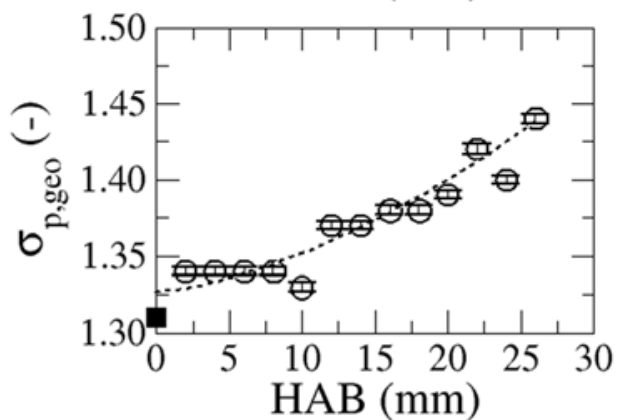

- SLS+SAXS+LII

... Fit

- TEM/SMPS/PPS (HAB=0 mm)

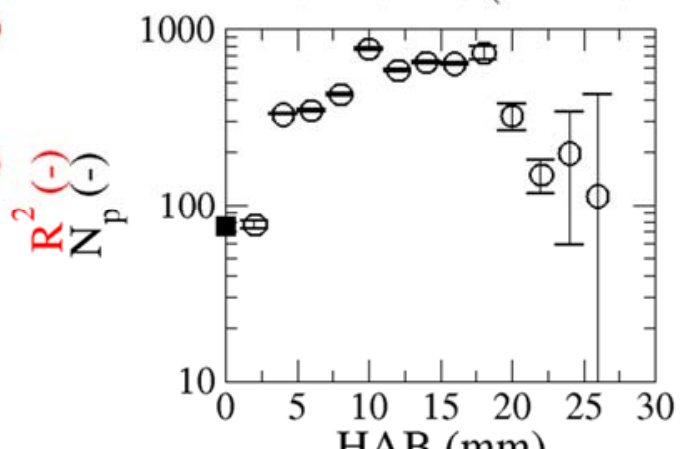

$\mathrm{HAB}(\mathrm{mm})$

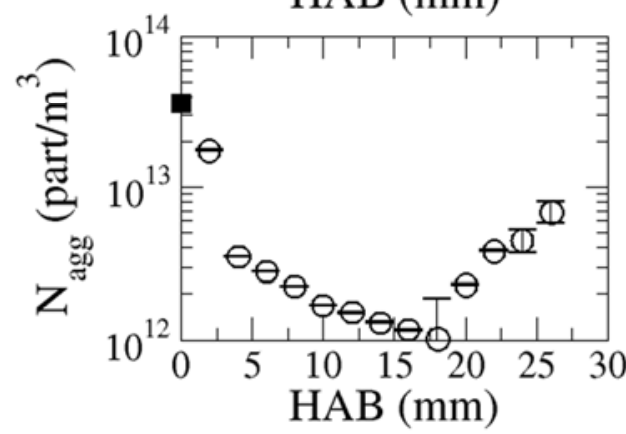

Fig. 8. Result of the SLS/SAXS/LII data inversion. Reported values at HAB $=0 \mathrm{~mm}$ correspond to the values determined on fresh soot by non-optical methods (TEM/SMPS/PPS-TEOM). 
.... Initial distribution at $\mathrm{HAB}=0 \mathrm{~mm}$

- SAXS result

Aging model
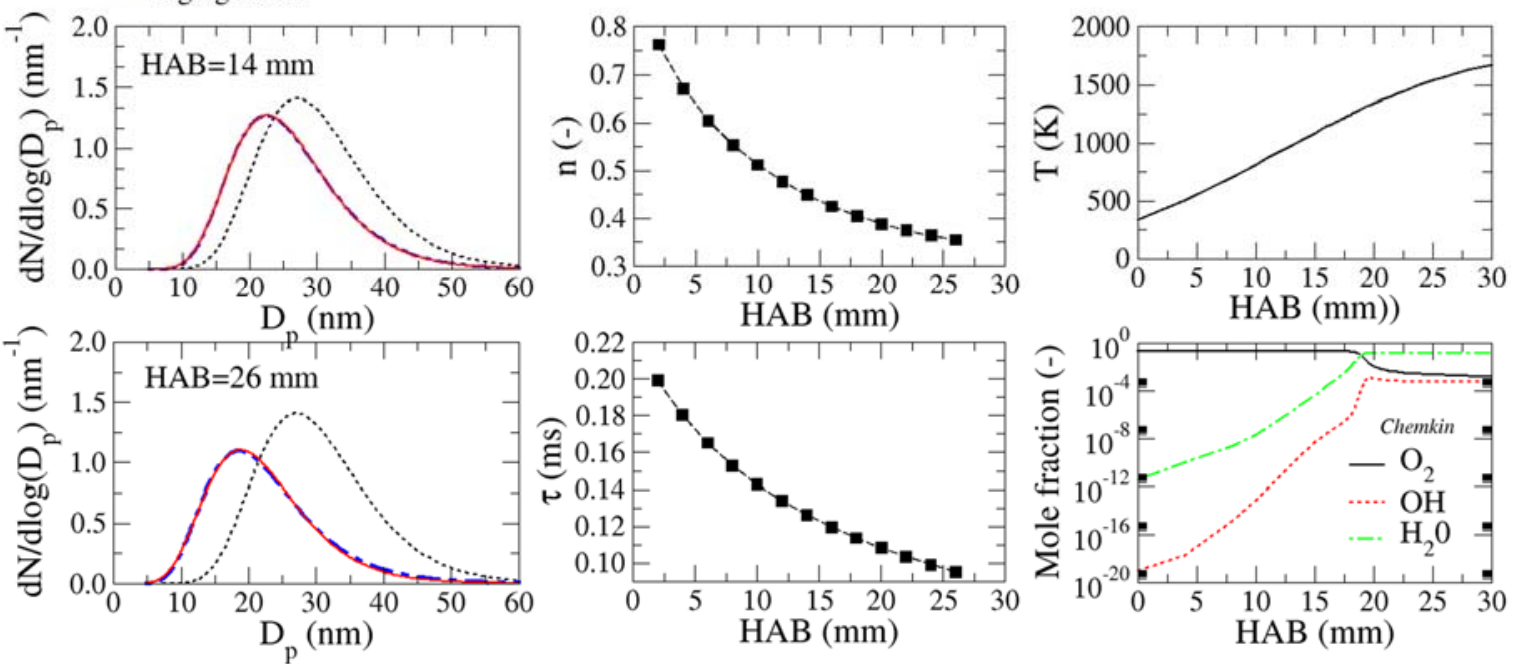

Fig. 9. Application of the model $\frac{d \widetilde{D_{p}}}{d t}=-\frac{1}{\tau} \widetilde{D_{p}}$ for the description of the primary sphere modal diameter and geometric standard deviation behavior along the flame (two first left columns) corresponding temperatures and oxidant species evaluated with Chemkin (right column). 


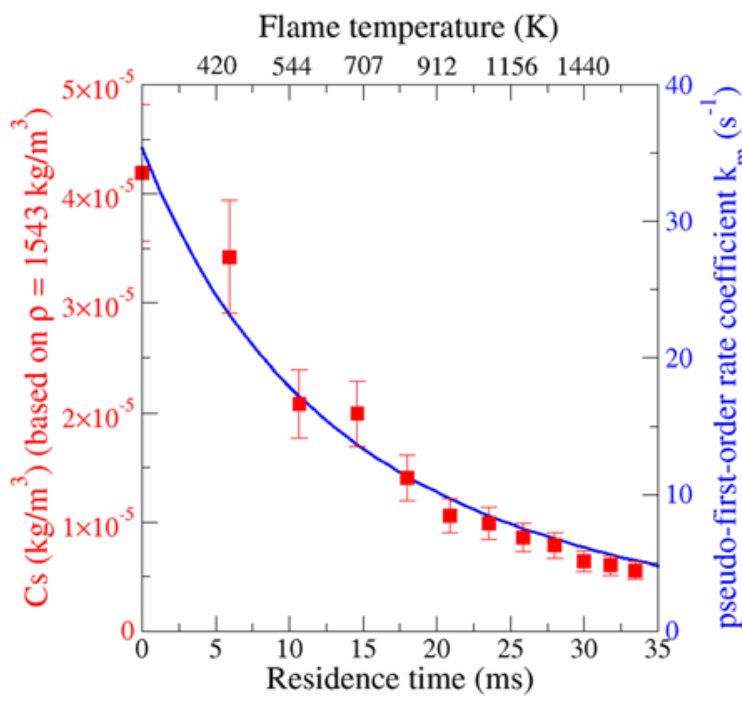

A: Mass concentration deduced from LII measurement (red full boxes) and determined pseudo-first-order rate of the oxidation process based on mass (blue solid curve).

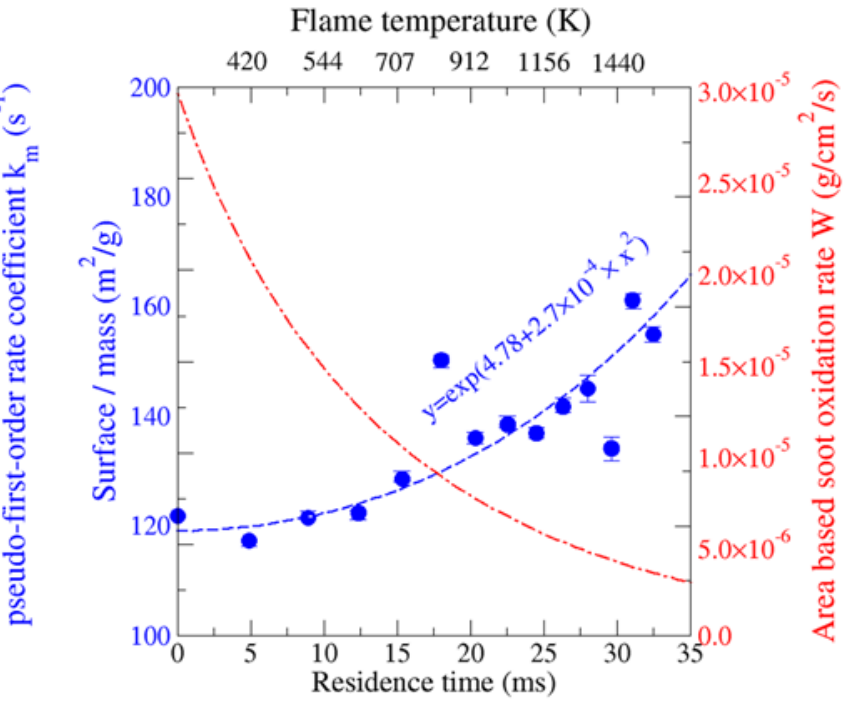

B: Aggregate surface - mass ratio (solid blue circles) and the area based soot oxidation rate (red dashed curve).

Fig. 10. Time evolution of the mass concentration and of the ratio surface/mass of the particles. 